\title{
Field Experiment on Soaking Characteristics of Collapsible Loess
}

\author{
Zhichao Wang, ${ }^{1}$ Yongli Xie, ${ }^{1}$ Junling Qiu, ${ }^{1}$ Yuwei Zhang, ${ }^{1}$ and Haobo Fan ${ }^{1,2}$ \\ ${ }^{1}$ Department of Geotechnical and Tunnel Engineering, Chang'an University, Xi'an 710064, China \\ ${ }^{2}$ China Railway Eryuan Engineering Group Co., Ltd., Chengdu 610000, China \\ Correspondence should be addressed to Junling Qiu; 870133597@qq.com
}

Received 29 June 2017; Accepted 27 August 2017; Published 17 October 2017

Academic Editor: Michael Aizenshtein

Copyright (C) 2017 Zhichao Wang et al. This is an open access article distributed under the Creative Commons Attribution License, which permits unrestricted use, distribution, and reproduction in any medium, provided the original work is properly cited.

\begin{abstract}
In collapsible loess area, migration of soil moisture often causes the temporal discontinuity and spatial nonuniformity of collapsibility, which leads to great damage for infrastructures. Therefore, the research on water infiltration is the key to solving the problem of collapsibility. The aim of this paper is to investigate the spatiotemporal evolution of infiltration characteristics of collapsible loess. A field soaking experiment was conducted on collapsible loess in western China, in which a soaking pool with diameter of $15 \mathrm{~m}$ was built. Time-Domain-Reflectometry (TDR) system and soil sampling were employed to measure the water content within the depth of $12 \mathrm{~m}$. Then the saturation isograms were drawn for visualization of the process of infiltration. Also, a pilot tunnel was excavated to investigate how the free face can affect the infiltration behaviors. The experimental results revealed the characteristics of infiltration in both horizontal and vertical directions. Moreover, the response of free face on infiltration behaviors was also found. These findings of research could provide the data for the infiltration laws of unsaturated loess and thereby provide the basis for integrated treatment of collapsible loess.
\end{abstract}

\section{Introduction}

Distribution of loess soil reaches $13,000,000 \mathrm{~km}^{2}$ in the world, covering about one-tenth of the earth. Loess is wind-brown sediment, which is typically formed in arid and semiarid areas with the widely known properties of macropores, root-like channels, and unsaturated structure. In engineering characteristics, collapsible loess belongs to a metastable structure which can withstand high vertical loads with a small amount of settlement at dry, but this soil is particularly susceptible to certain water conditions, which shows an upsurge in settlement and a plunge in load capacity upon wetting [1-8]. Collapsible loess is characterized by temporal discontinuity and spatial nonuniformity of collapsibility upon wetting, which contributes to a safety hazard for infrastructures constructed in this region [9-15]. The reason for that is the discontinuous and nonuniform variation of water content of loess soil. Therefore, it has become central issue for understanding of the spatiotemporal development of infiltration in natural loess.

Admittedly, the occurrence of loess collapsibility is closely correlated with the movement of water. Because of the interaction between moisture and air, the unsaturated infiltration properties of loess soil are rather complicated [1620]. At present, ample researches have been conducted on matrix suction of loess in theory and laboratory [21-27], which is considered as an essential parameter in unsaturated soil and can reveal the moving direction of moisture and the interaction between moisture and air. Gavin and Xue [28] successfully predicted the time needed for the wetting front development by using the modification of traditional GreenAmpt infiltration model. Munoz-Castelblanco et al. [29] summarized water retention properties of unsaturated loess in northern France and observed its microstructure; Haeri et al. [30] obtained the suction stress characteristic curve for collapsible loess to describe the constitutive relationship between matrix suction and suction stress; Zhou et al. [31] summarized the results of laboratory test and analyzed instability mechanism of loess slope subjected to water infiltration. Compared with laboratory test, the field experiment can maintain the original structure, water content, and stress status of natural soil; in particular, the actual seepage field can be observed, which is irreplaceable by laboratory test. Meanwhile, in situ measurement of water content is the key 


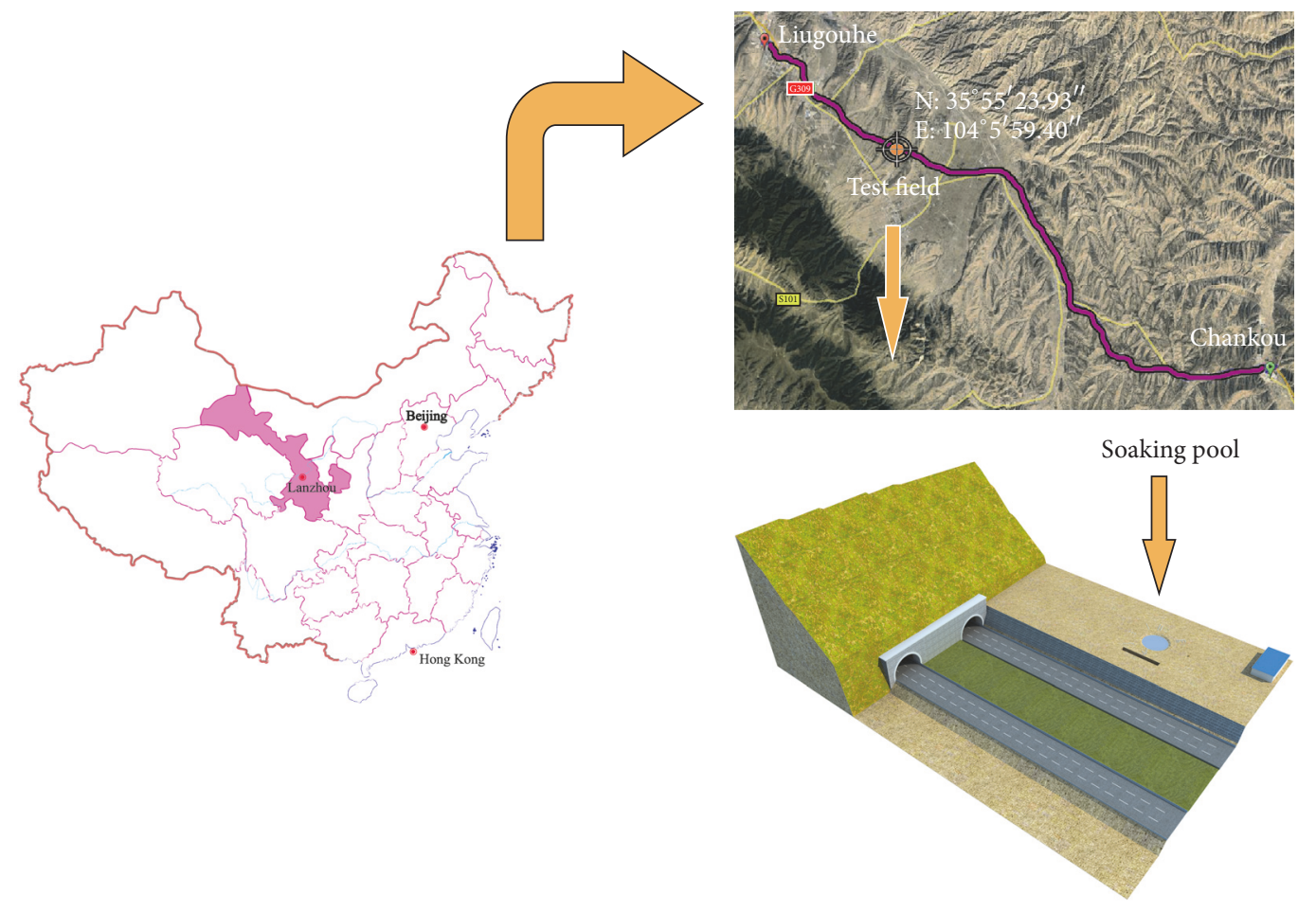

Figure 1: Panorama of test field.

to providing the direct expression for the process of water infiltration [32]. Tu et al. [33] disclosed the infiltration process of rainwater into shallow loess through field monitoring in loess plateau, China; Wu [34] constructed a soaking pit with the diameter of $20 \mathrm{~m}$ to study the loess collapsibility and the process of water infiltration and dissipation in Donghai, China; Kong et al. [35] and Wang et al. [36] built a soaking pit with the diameter of $40 \mathrm{~m}$ so as to research the loess collapsibility and vertical infiltration laws in Lanzhou, China.

However, research on spatiotemporal law of infiltration remains to be further studied and there are no observations from the perspective of horizontal infiltration behaviors in unsaturated loess. Moreover, little research results have been reported concerning how the free face influences the seepage field.

The main aim of the present experiment is to explore the infiltration characteristics of collapsible loess. By establishing a soaking pool with diameter of $15 \mathrm{~m}$, a large-scale field soaking experiment was conducted on collapsible loess in Lanzhou, China. Using the methods of Time-DomainReflectometry (TDR) system and soil sampling test, the behaviors of migration of soil moisture and its response impacted by free face were studied, respectively.

\section{Description of Test Field}

The Chankou-Liugouhe Highway is an important part of Lianyungang-Horgos Highway throughout Chinese mainland from east to west. It starts from Chankou in the east and ends in Liugouhe in the west with a total length of $77.7 \mathrm{~km}$, which is also an important economic main artery in western China.
TABLE 1: Soil parameters.

\begin{tabular}{lcccc}
\hline $\begin{array}{l}\text { Soil } \\
\text { thickness }\end{array}$ & \multicolumn{2}{c}{$\begin{array}{c}\text { Collapsibility } \\
\text { coefficient } \delta_{S}\end{array}$} & \multicolumn{2}{c}{$\begin{array}{c}\text { Self-weight } \\
\text { collapsibility } \\
\text { coefficient } \delta_{S Z}\end{array}$} \\
& Average & Maximum & Average & Maximum \\
\hline $0-15 \mathrm{~m}$ & 0.072 & 0.136 & 0.049 & 0.126 \\
\hline
\end{tabular}

The test field is located at the south side, outside west tunnel portal of Xinzhuangling tunnel $(\mathrm{K} 60+818-\mathrm{K} 62+240)$, Chankou-Liugouhe Highway, as shown in Figure 1. According to geological data and laboratory test data, the thickness of self-weight collapsible loess is approximately $15 \mathrm{~m}$ and collapsible grade is IV, and soil parameters surveyed from exploratory well (depth of $15 \mathrm{~m}$ ) are shown in Table 1 (as detailed in Tables 2 and 3). Based on field investigation, there is an irrigation canal above Xinzhuangling tunnel, which irrigates the area for 6 to 8 times annually. Meanwhile, the water intake point of west-route of the South-to-North Water Transfer Project is only dozens of kilometers away from Xinzhuangling tunnel, which will be unified with current irrigation system. On this occasion, the large increase of water will cause huge hidden danger for the safety of existential tunnels [37-41]. Therefore, performing the large-scale field soaking experiment near Xinzhuangling tunnel has great engineering significance.

\section{Methodology}

3.1. Experimental Design. To meet the complete occurrence of collapsibility and eliminate the impact of surface 


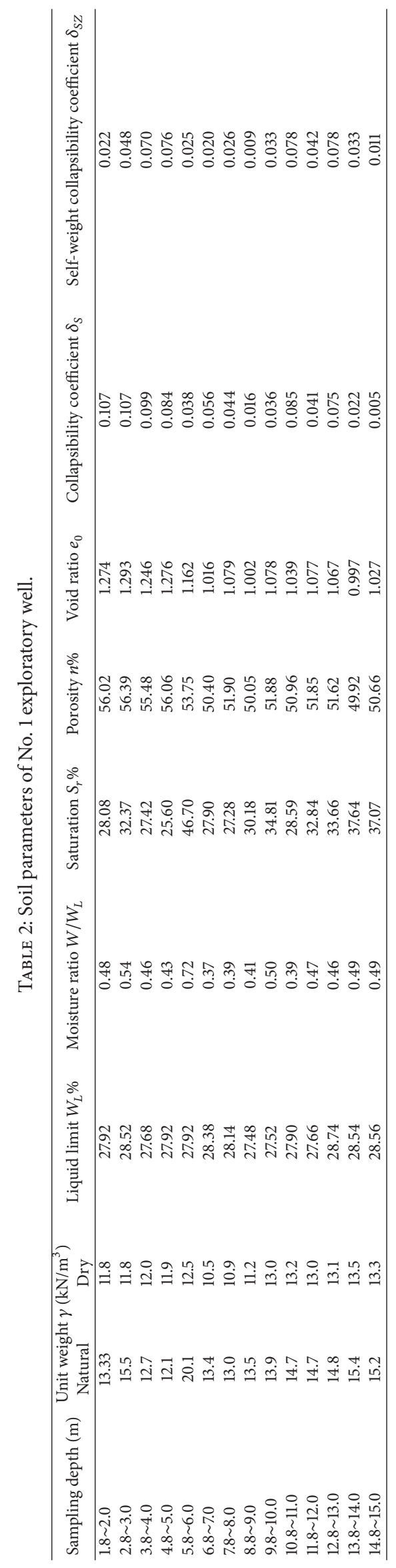




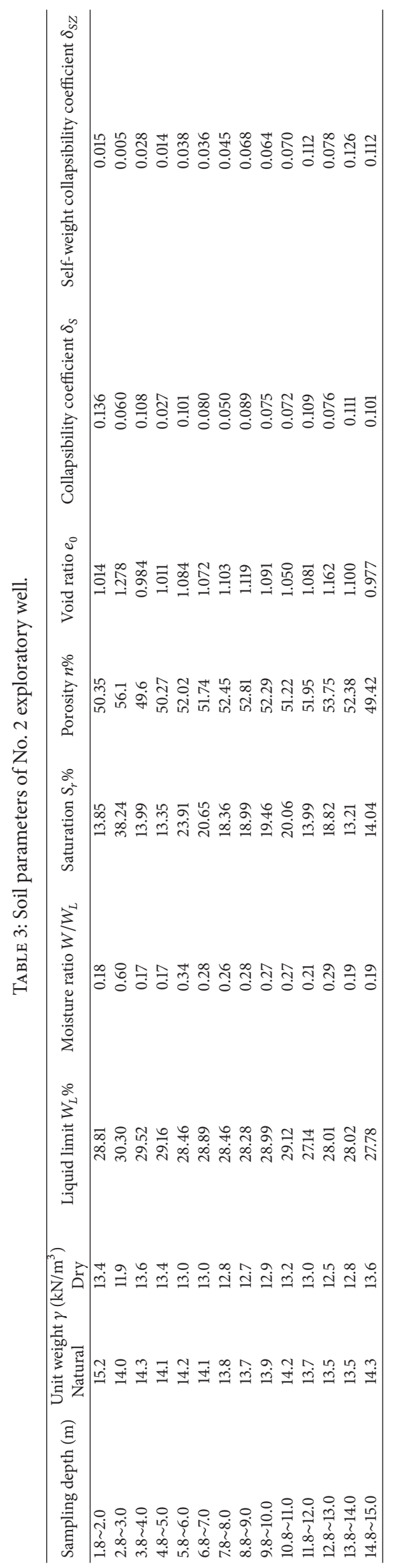


cultivation [32], a circular soaking pool was built with diameter of $15 \mathrm{~m}$ and depth of $50 \mathrm{~cm}$, as shown in Figure 2. Sidewall of soaking pool used waterproofing and the bottom of pool used washed sand so as to form the downward movement of water. The water level was kept at $15 \mathrm{~cm}$, which came from phreatic water (depth of $210 \mathrm{~m}$ ). And a circular shed with diameter of $20 \mathrm{~m}$ was equipped to decrease the impact of climate. Meanwhile, with the aim of understanding how the free face impact on the behavior of water infiltration, a pilot tunnel in the soil trough was excavated to simulate existential tunnel, which was supported by steel plates and wooden poles [42-44]. The experiment lasted for 65 days.

TRIME-TDR tube access probe (IMKO Inc., Ettlingen, Germany) was employed for continuous and nondestructive determination of volumetric soil moisture, which is based on Time-Domain-Reflectometry (TDR) technique [45-48]. A total of 95 TRIME-TDR probes were installed, as shown in Figure 2. In detail, probes number 1 to number 7 were installed in central line of soaking pool, in which probe number 4 was at the center, probe number 5 was at the radial center, probes number 3 and number 6 were $30 \mathrm{~cm}$ away from the rim, and probes number 1 , number 2 , and number 7 were at extending line of the rim. The farther from the soaking pool, the deeper development of the wetting front $[30,32]$. Hence, probes number 1 and number 2 were installed after the ground was excavated to $2 \mathrm{~m}$ and $1 \mathrm{~m}$, respectively. Probes number 8 to number 10 were installed horizontally in soil trough for measuring the horizontal infiltration data (Figure 2(b)). Also, the other probes were installed along the line of $\mathrm{OA}, \mathrm{OA}^{\prime}, \mathrm{OB}, \mathrm{OB}^{\prime}, \mathrm{OC}, \mathrm{OD}, \mathrm{OD}^{\prime}, \mathrm{OE}, \mathrm{OF}$, and $\mathrm{OF}^{\prime}$ and in soil trough (Figures 2(a) and 2(c)).

3.2. Measuring Scheme. Before soaking, water content was measured and recorded as the initial value. After soaking, water content was measured continuously. Subsequently, the measurement period was gradually increased with the interval of 20 mins, 40 mins, 60 mins, and so forth. Meanwhile, to overcome the inadequate length of measurement of TRIMETDR probes (length of $3 \mathrm{~m}$ ), Luoyang shovel was used for soil sampling to measure mass water content at a certain time. Luoyang shovel is a kind of archaeological tool with half cylindrical shovel, which is widely applied as a common tool of sampling in Chinese geotechnical engineering, as shown in Figure 3. The sampling method was to take soil samples every $20 \mathrm{~cm}$ depth for measuring its mass water content by ovendrying method, and the interval of sampling was the same as that of TRIME-TDR probes; then the sampling holes were tamped.

3.3. Data Processing. The data collection, processing, analysis, and management were based on the comprehensive data processing system, which was programmed by Visual $\mathrm{C}++$, Matlab, and Microsoft Access. Due to small spacing of measurement $(20 \mathrm{~cm})$, linear interpolation method was used for data algorithm. To describe the spatiotemporal evolution of infiltration behaviors, saturation isograms were drawn by each discrete point of degree of saturation (\%), which was transformed from volumetric water content measured by TRIME-TDR probes and mass water content measured by soil sampling. Porosity and dry density were taken from laboratory test, as detailed in Tables 2 and 3.

\section{Experimental Results}

\subsection{Infiltration Behavior of Shallow Soil}

4.1.1. Soaking Period. Figure 4 presents the distribution of the degree of saturation varying with soaking time. In Figures 4(a)-4(d), it can be observed that moisture moved downward by the combined efforts of gravity and matrix suction, and the wetting front moved downward to $1.7 \mathrm{~m}$, while little horizontal movement developed after soaking for 10 hours. In Figure 4(e), the wetting front moved downward to $2.2 \mathrm{~m}$ and broke through the left edge of soaking pool within the depth of 0.5 to $1.4 \mathrm{~m}$. Comparing Figures $4(\mathrm{e})-4(\mathrm{~m})$, it can be seen that the horizontal wetting front developed gradually. Interestingly, the wetting front did not nearly extend horizontal boundary of unsaturated zone but moved downward. Also in Figure 4(m), the horizontal wetting front remained in 3 to $4 \mathrm{~m}$ away from the edge of soaking pool. Apparently, under the force of gravity and matrix suction, the speed of wetting front moving downward was strikingly faster than that in horizontal direction. It can be indicated that the movement of wetting front is due mainly to gravity and secondarily to matrix suction. As time goes on, there was an obvious difference in saturation isolines on both left and right sides of soaking pool (see Figure $4(n)$ ); it can be seen that the unsaturated zone on the left was larger than that on the right. There are three possibilities for this behavior. First, the porosity of soil on the left side is bigger than that on the right side, which results in the difference of horizontal infiltration coefficient. Second, the content of collapsibility on the left side is larger than that on the right side, which causes different hydraulic head. Third, the boundary conditions of seepage field are changed by the free face on the left side.

4.1.2. Water Cutoff Period. Figure 5 displays the distribution of the degree of saturation as the time of water cutoff. It can be seen that the smaller the depth was, the faster the saturation decreased. Based on observation, the degree of saturation within the depth of $2 \mathrm{~m}$ decreased fast because the soil close to the surface dries fast. However, the rate of decline of water content was less than $1 \%$ per day beyond depth of $2 \mathrm{~m}$. We may conclude that deep soil slowly replenishes the air, which depends on the conduction of seepage field. Due to the low permeability, the degree of saturation of deep soil shows a slow-moving decrease.

Also, we could infer that unsaturated loess undergoes five stages at different depth. (1) Loess soil is in natural unsaturated status before soaking. (2) Loess soil is in unsaturated seepage status when wetting front passes. (3) Loess soil is in saturated seepage status after wetting front passes. (4) Loess soil is in unsaturated seepage status again after water cutoff. (5) Loess soil returns to natural unsaturated status after a period of water cutoff.

4.2. Infiltration Behavior of Deep Soil. During the test, the samples were taken from 10 vertical profiles along radial 


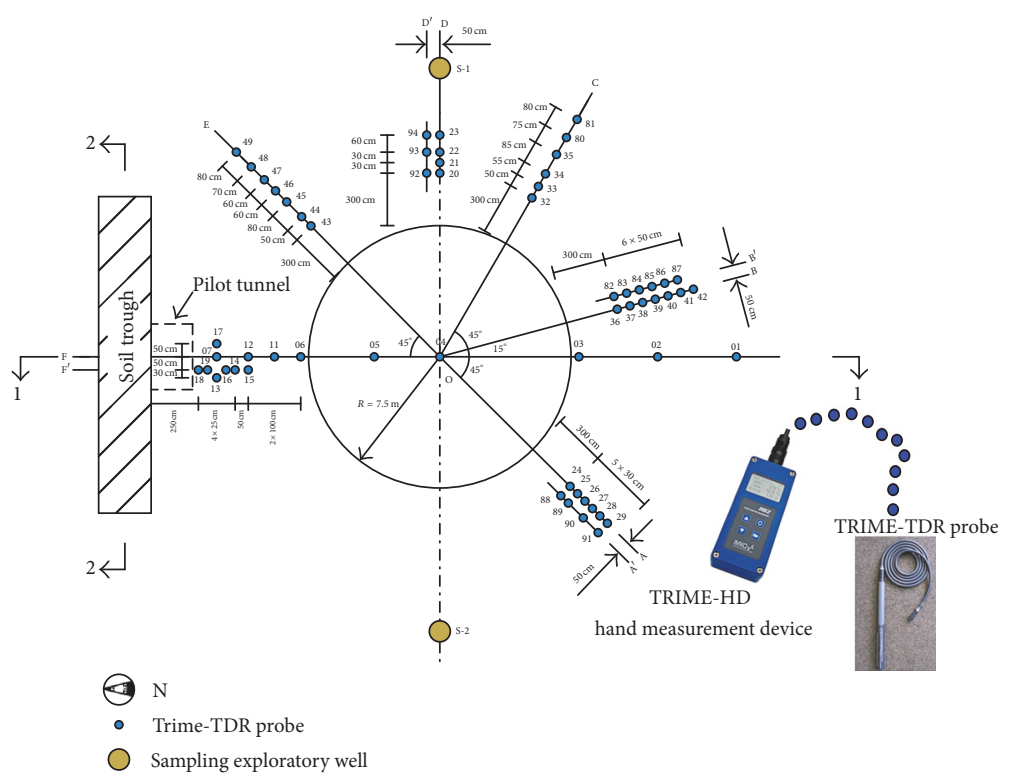

(a)

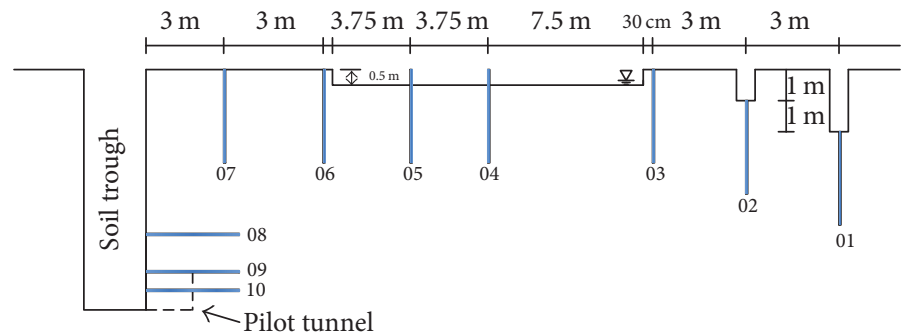

(b)

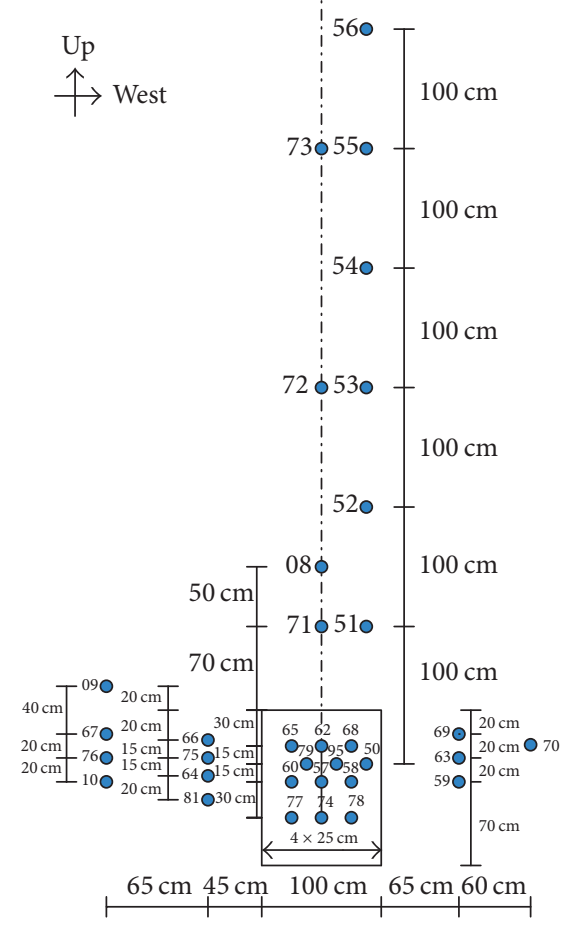

(c)

FIgURE 2: TRIME-TDR layout plan for soaking experiment. (a) An aerial view. (b) A side view from 1-1 cross section. (c) A side view from 2-2 cross section. The black arrows (1-1 and 2-2) represent the cross sections, which could reflect the layout plan of soaking experiment from different perspectives. 


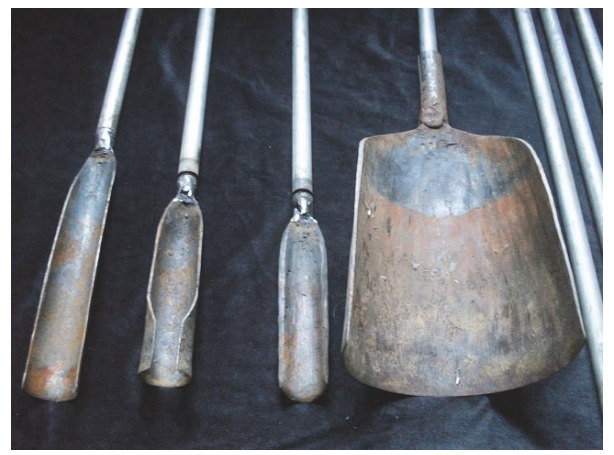

FIGURE 3: Luoyang shovel.

direction of soaking pool by Luoyang shovel with the different depth of 8 to $12 \mathrm{~m}$. In combination with the data measured by TRIME-TDR probes, the saturation isograms of different vertical profiles can be drawn, as shown in Figure 6.

In Figures 6(a) and 6(b), the unsaturated wetting front was fairly obvious and the maximum degree of saturation was $80 \%$ within 1 to $3 \mathrm{~m}$ away from soaking pool. The saturation of shallow soil was within the scope of natural saturation; hence, shallow soil was unaffected by soaking. Meanwhile, the saturation of deep soil was bigger than natural saturation and the saturation of middle soil reached the maximum, which was obviously affected by soaking. The shape of saturation isolines was approximately a part of an ellipse. It can be indicated that unsaturated infiltration pattern is approximately ellipsoid in early period of soaking.

In Figures 6(c) and 6(d), the maximum degree of saturation was $60 \%$, which was less than $80 \%$ (Figures 6 (a) and $6(\mathrm{~b}))$. That is because the distance to soaking pool is farther than the previous two.

By comparing Figure 6(e) with Figure 6(f), the saturation isolines of $70 \%$ almost presented no horizontal movement, while those of $60 \%$ showed a small amount of horizontal movement and those of $50 \%$ showed a considerable amount of horizontal movement. Particularly, it can be seen that another surface water source (melted snow) in the upper right area affected the infiltration behavior (see Figure 6(e)).

According to Figures 6(g) and 6(h), it can be seen that the degree of saturation increased with the growth of depth. And the saturation isolines of $50 \%$ and $60 \%$ hardly had horizontal movement, while those of $40 \%$ showed a large amount of horizontal movement. It can also be seen that the saturation isolines were almost vertical downward, which represented the edge of seepage field in OB direction at this moment (see Figure 6(g)). In Figures 6(i) and 6(j), the horizontal scope of infiltration of OC profile was $6 \mathrm{~m}$ and that of OE profile was $5.5 \mathrm{~m}$ away from the edge of soaking pool when the soaking time was 48 days. From Figures $6(\mathrm{~g})-6(\mathrm{j})$, it can be seen that the saturation isolines almost distributed vertically in midto-late period of soaking, which could lead to the conclusion that the moisture mainly moves downward due to gravity. And the horizontal movement of isolines with the degree of saturation of more than $50 \%$ stagnated, while isolines of lower degree of saturation (less than 50\%) moved quite slowly. It appears that the horizontal movement of isolines with high degree of saturation (more than 50\%) is mainly driven by water pressure from higher saturation zone, while that with low degree of saturation (less than $50 \%$ ) is mainly driven by matrix suction.

4.3. Infiltration Behavior Affected by Free Face. In order to understand how the free face can affect the infiltration behavior, a horizontal pilot tunnel was excavated from soil trough in depth of $7 \mathrm{~m}$ towards the center of soaking pool after soaking for 38 days. The response of infiltration behavior after the excavation of pilot tunnel is displayed in Figure 7. It can be observed that the degree of saturation around pilot tunnel increased gradually, and the movement patterns of soil moisture presented " $V$ " shape. It appears that free face can accelerate the horizontal movement of wetting front in unsaturated zone.

Figure 8 presents the horizontal variation of saturation, both inside and outside the pilot tunnel. It can be observed that the degree of saturation within pilot tunnel was greater than that outside pilot tunnel in the vicinity of free face. Gradually, the degree of saturation, both inside and outside pilot tunnel, tended to be consistent with longer distance to free face. Comparing Figures $8(\mathrm{a})-8(\mathrm{c})$, within the distance of $1.5 \mathrm{~m}$ away from free face, the degree of saturation inside pilot tunnel increased up to a steady value (50\% to $60 \%)$ as time goes by. There are two aspects for this behavior. On one hand, the influence range of free face is limited when free face and wetting front are a longer distance apart. On the other hand, the increased degree of saturation makes the motion of air more difficult. It could be concluded that free face has an obvious impact on horizontal infiltration behavior with saturation of less than $50 \%$ and within the distance of $1.5 \mathrm{~m}$ away from free face.

\section{Discussion}

The paper aims at exploring the infiltration characteristics of collapsible loess. Based on the above experiment, the speed of downward movement of wetting front was obviously far greater than that of horizontal movement, which indicates that the property of permeation has typical anisotropism. The 


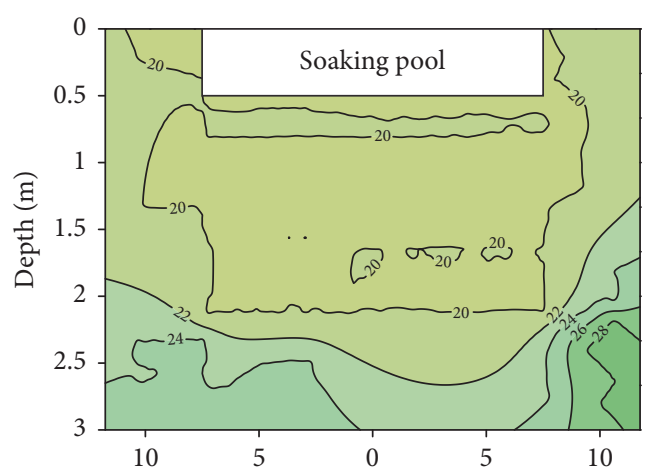

Horizontal distance to soaking pool center $(\mathrm{m})$

(a) $t=0 \mathrm{~h}$

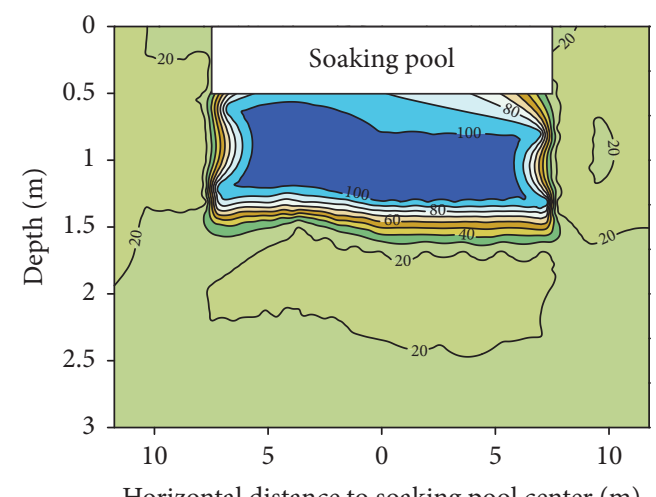

Horizontal distance to soaking pool center (m)

(c) $t=5 \mathrm{~h}$

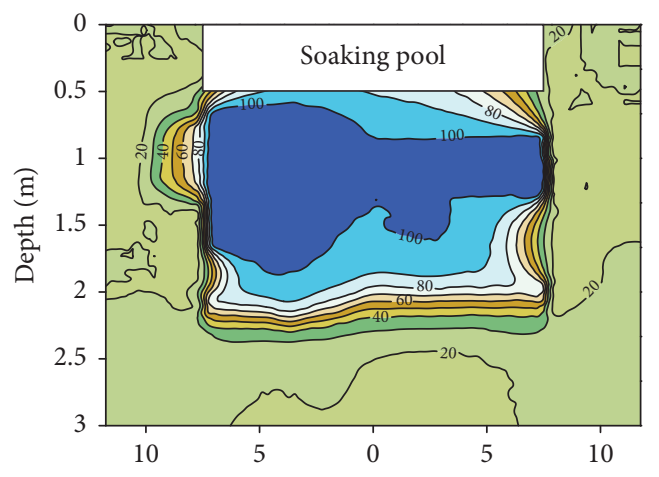

Horizontal distance to soaking pool center (m)

(e) $t=15 \mathrm{~h}$

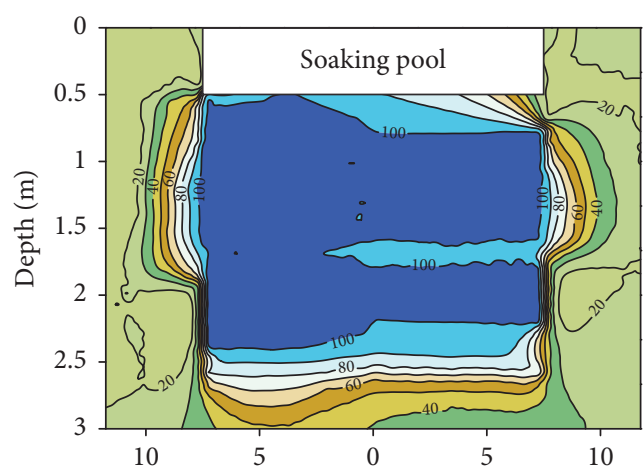

Horizontal distance to soaking pool center (m)

(g) $t=25 \mathrm{~h}$

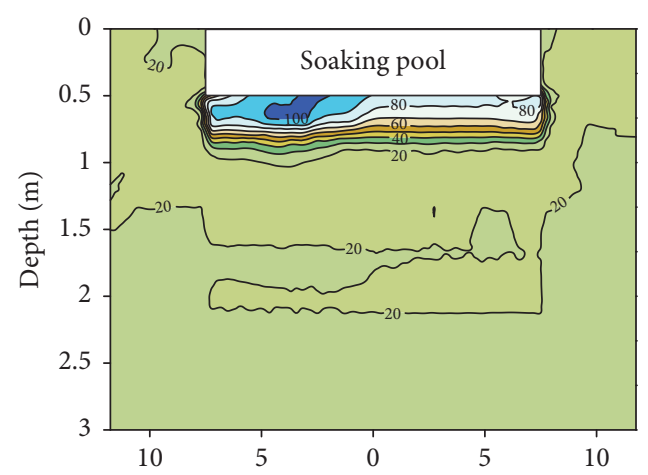

Horizontal distance to soaking pool center (m) (b) $t=1 \mathrm{~h}$

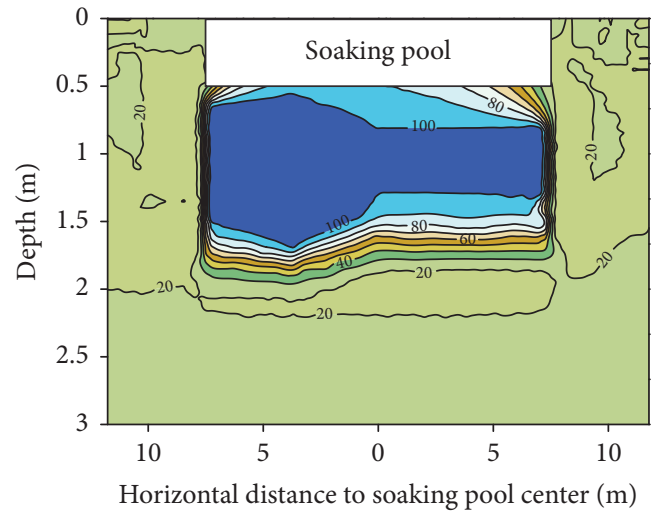

(d) $t=10 \mathrm{~h}$

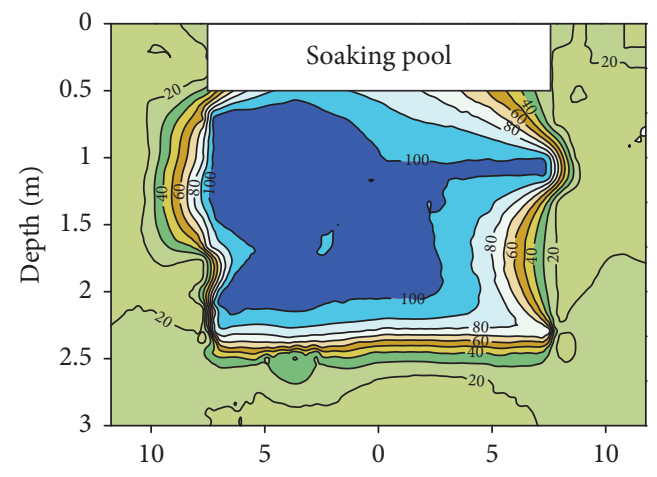

Horizontal distance to soaking pool center $(\mathrm{m})$

(f) $t=20 \mathrm{~h}$

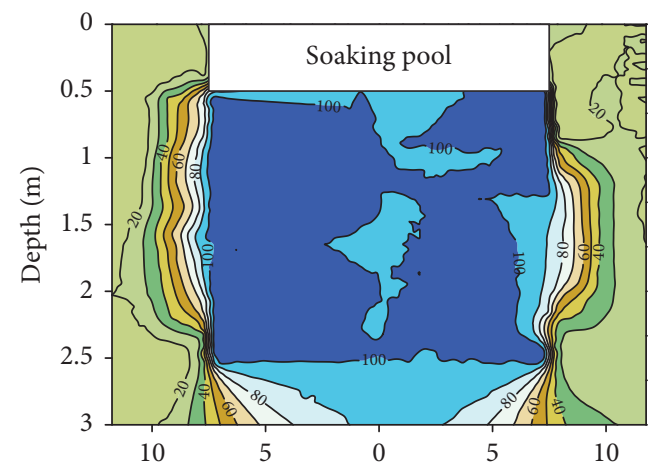

Horizontal distance to soaking pool center (m)

(h) $t=30 \mathrm{~h}$

Figure 4: Continued. 


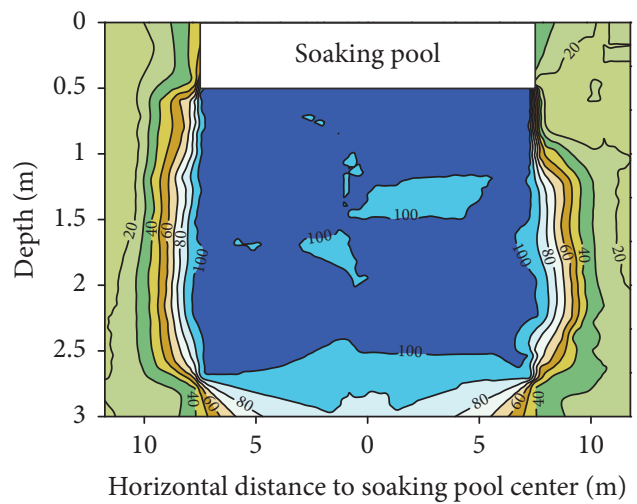

(i) $t=40 \mathrm{~h}$

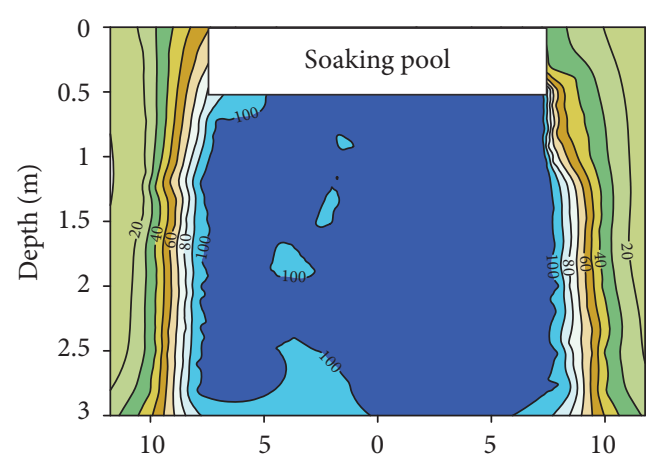

Horizonal distance to soaking pool center (m)

(k) $t=100 \mathrm{~h}$

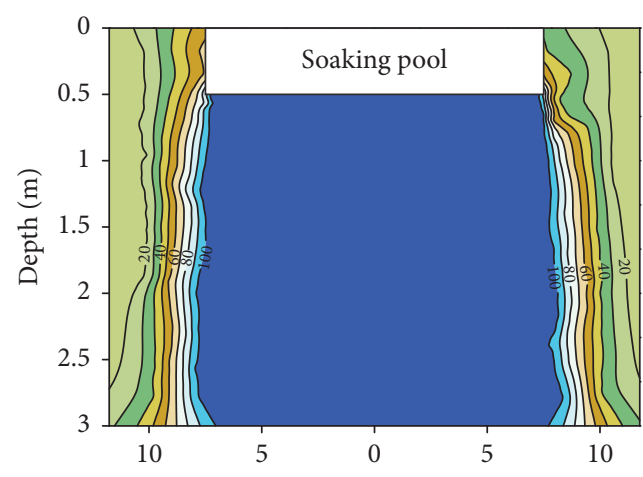

Horizontal distance to soaking pool center (m)

(m) $t=15 \mathrm{~d}$

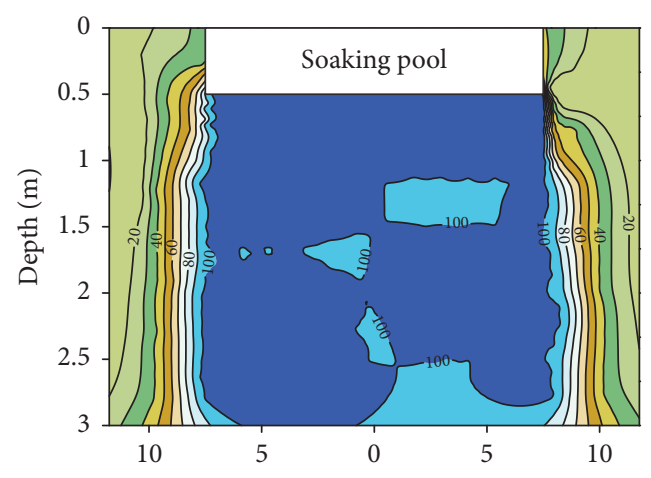

Horizontal distance to soaking pool center (m)

(j) $t=50 \mathrm{~h}$

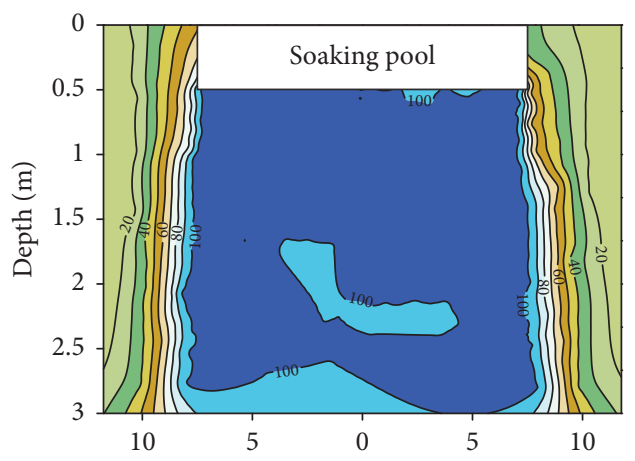

Horizontal distance to soaking pool center $(\mathrm{m})$

(1) $t=10 \mathrm{~d}$

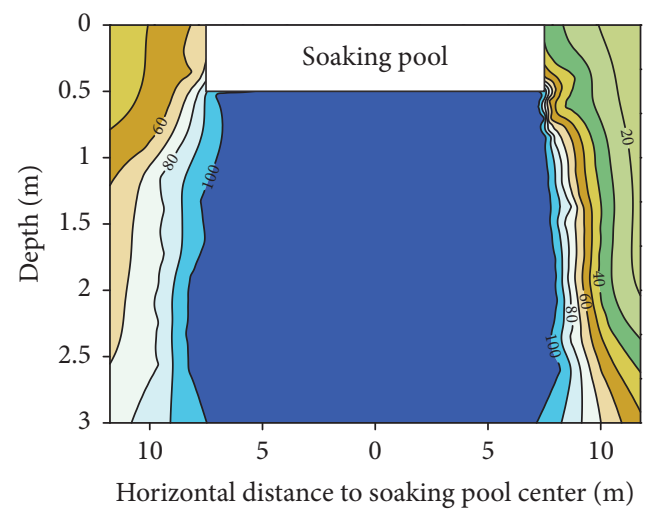

(n) $t=30 \mathrm{~d}$

FIGURE 4: Saturation isograms within the depth of $3 \mathrm{~m}$ at different soaking stages. (a-n) represent the soaking time of $t=0$ to $30 \mathrm{~d}$, respectively.

inequivalence of infiltration characteristic in both directions will be discussed as follows.

5.1. Saturation Permeability. Based on the code of Test Methods of Soils for Highway Engineering, variable head permeability test was used for measuring the saturation permeability of undisturbed loess $[49,50]$. The laboratory test results are given in Table 4 .

Figure 9 reports the results for the average saturation permeability in vertical and horizontal directions. It can be seen that the vertical hydraulic conductivity was slightly larger than the horizontal hydraulic conductivity. The small difference of hydraulic conductivity in both directions lies in the occurrence of collapsibility, which causes the failure of natural structure of loess.

5.2. Unsaturated Permeability. In this paper, the arrival time of water at various depths was measured as shown in Table 5. The vertical infiltration characteristics showed that the wetting front moves downward rapidly in shallow soil and its movement gradually decreased with an increase of depth, which is consistent with the results reported in the literature $[34,36]$. There are two main reasons for this characteristic: (1) the pore resistance and the friction increase with an increase 


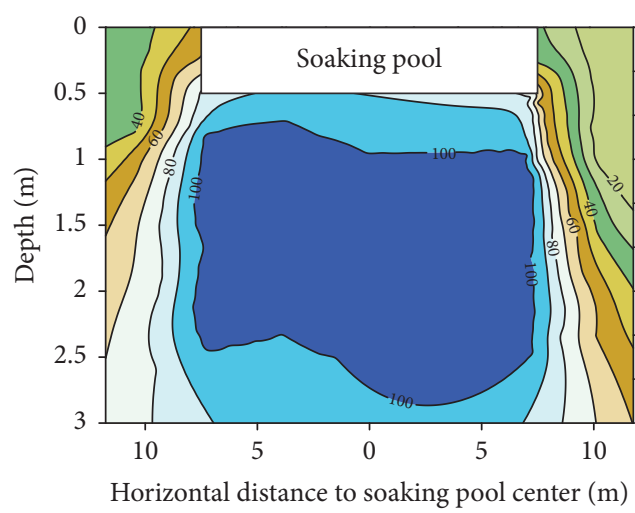

(a) $t=1 \mathrm{~d}$

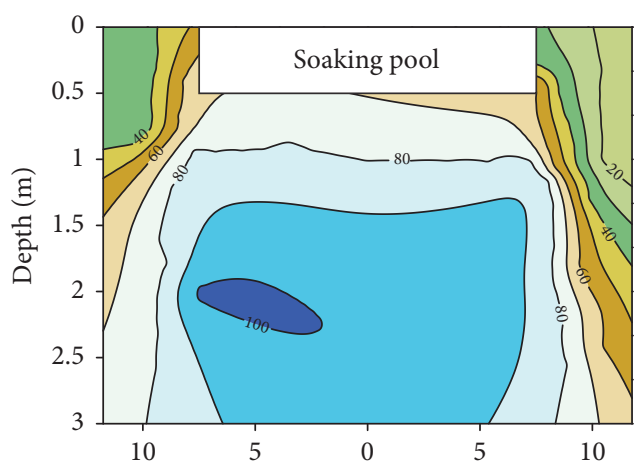

Horizontal distance to soaking pool center (m)

(c) $t=3 \mathrm{~d}$

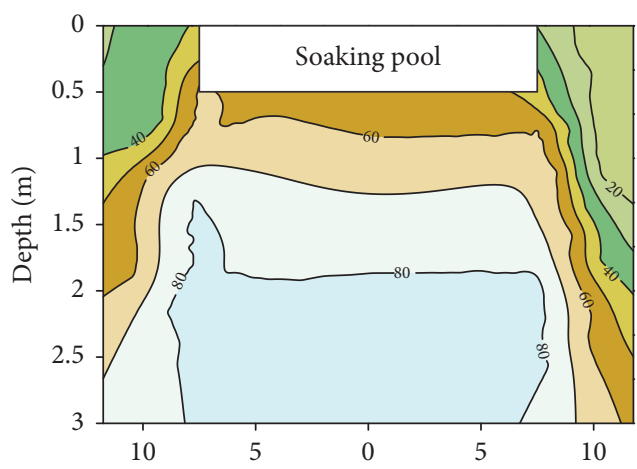

Horizontal distance to soaking pool center $(\mathrm{m})$

(e) $t=5 \mathrm{~d}$

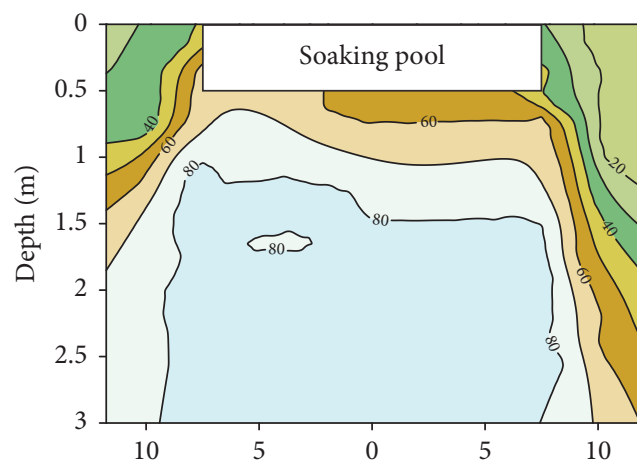

Horizontal distance to soaking pool center $(\mathrm{m})$

(g) $t=7 \mathrm{~d}$

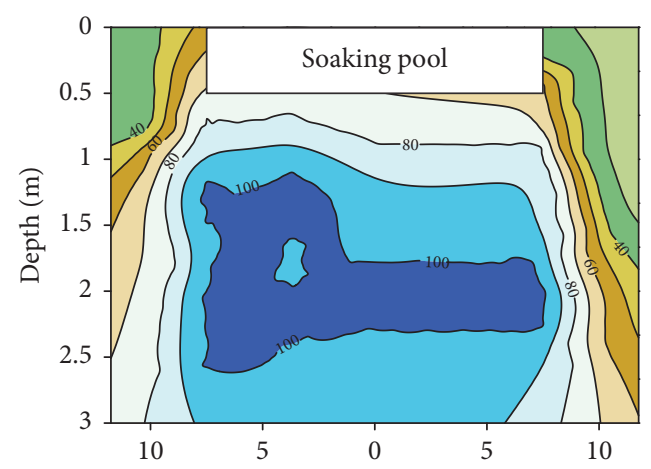

Horizontal distance to soaking pool center (m)

(b) $t=2 \mathrm{~d}$

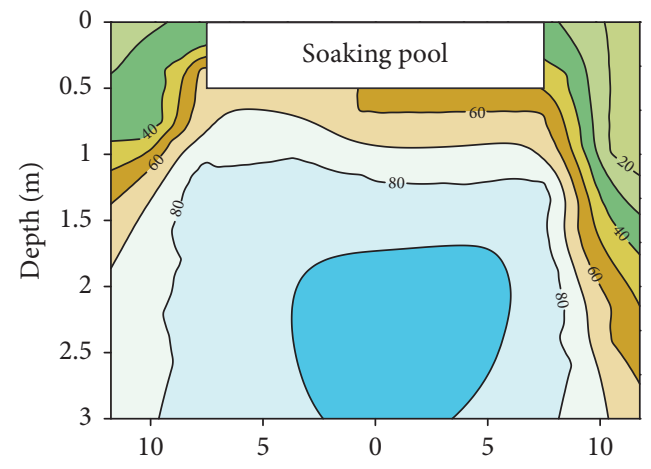

Horizontal distance to soaking pool center $(\mathrm{m})$

(d) $t=4 \mathrm{~d}$

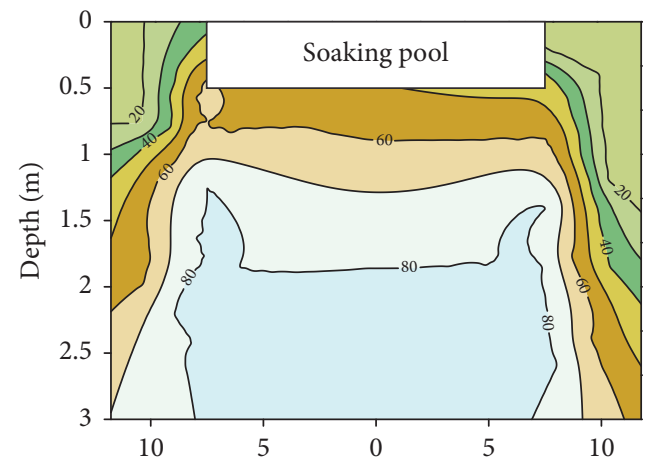

Horizontal distance to soaking pool center $(\mathrm{m})$

(f) $t=6 \mathrm{~d}$

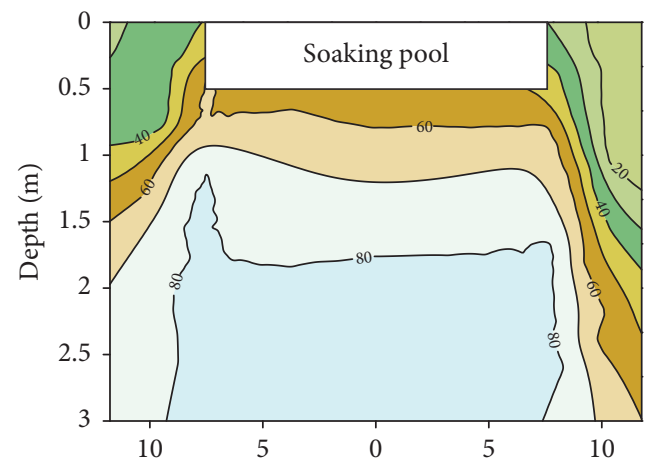

Horizontal distance to soaking pool center $(\mathrm{m})$

(h) $t=8 \mathrm{~d}$

FIGURE 5: Saturation isograms within the depth of $3 \mathrm{~m}$ at different water cutoff stages. (a-h) represent the water cutoff time of $t=1$ to $8 \mathrm{~d}$, respectively. 


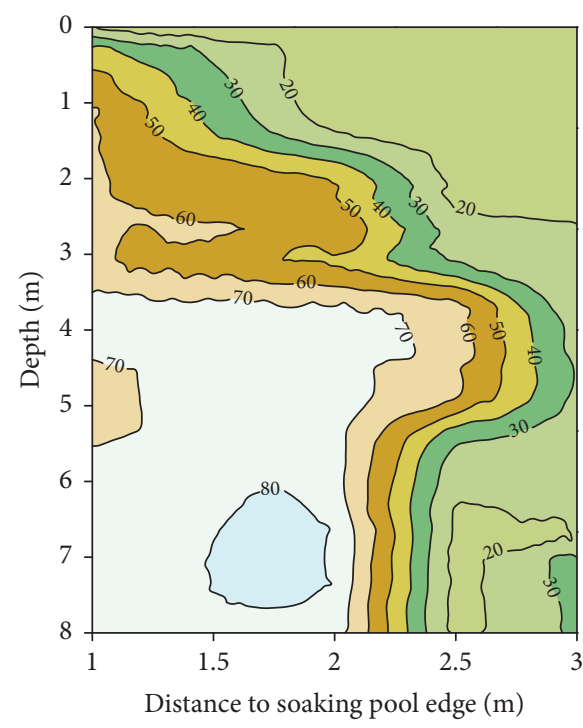

(a) $t=10 \mathrm{~d}$ on OF profile

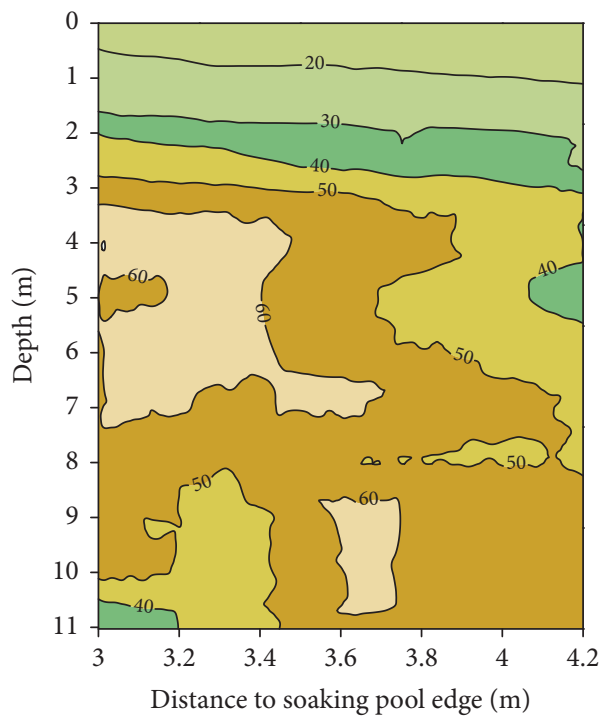

(c) $t=24 \mathrm{~d}$ of OD profile

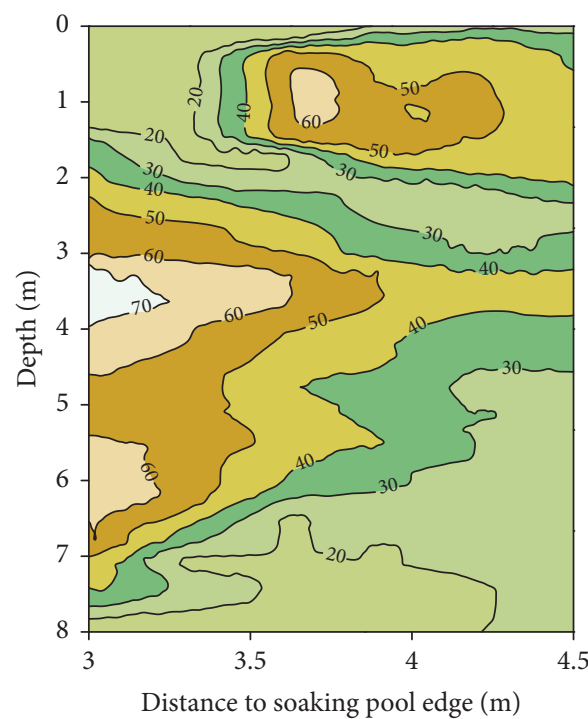

(e) $t=29 \mathrm{~d}$ on OA profile

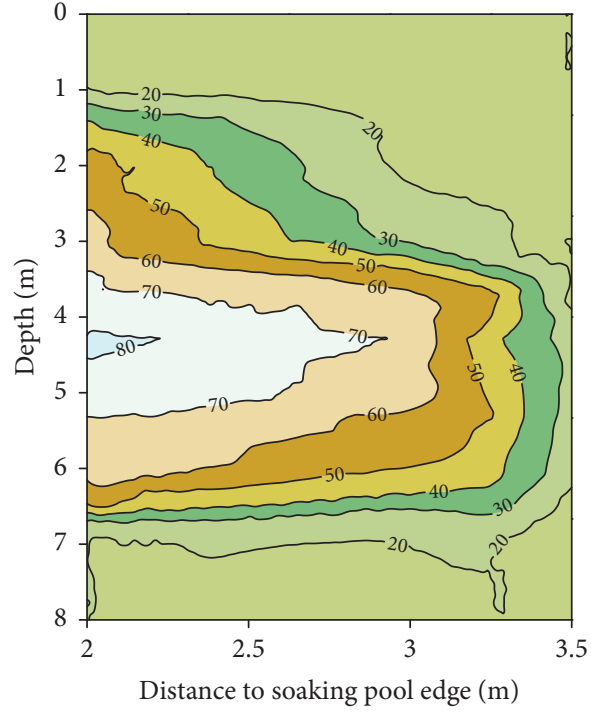

(b) $t=15 \mathrm{~d}$ on $\mathrm{OF}^{\prime}$ profile

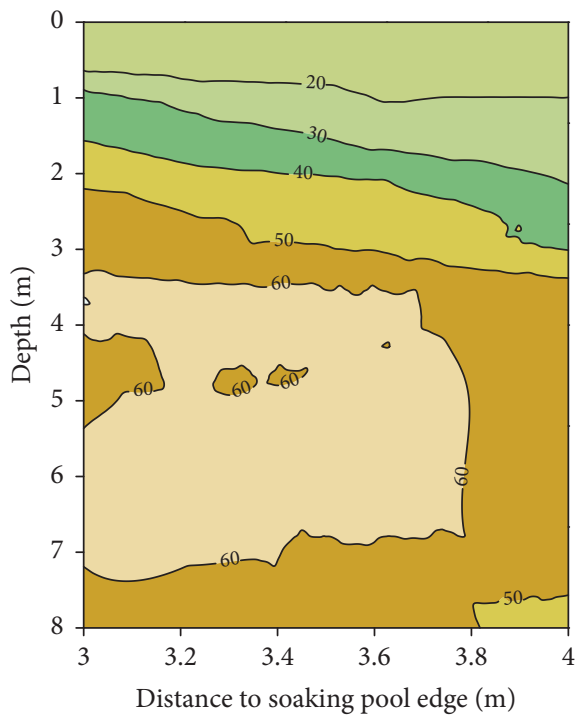

(d) $t=55 \mathrm{~d}$ on $\mathrm{OD}^{\prime}$ profile

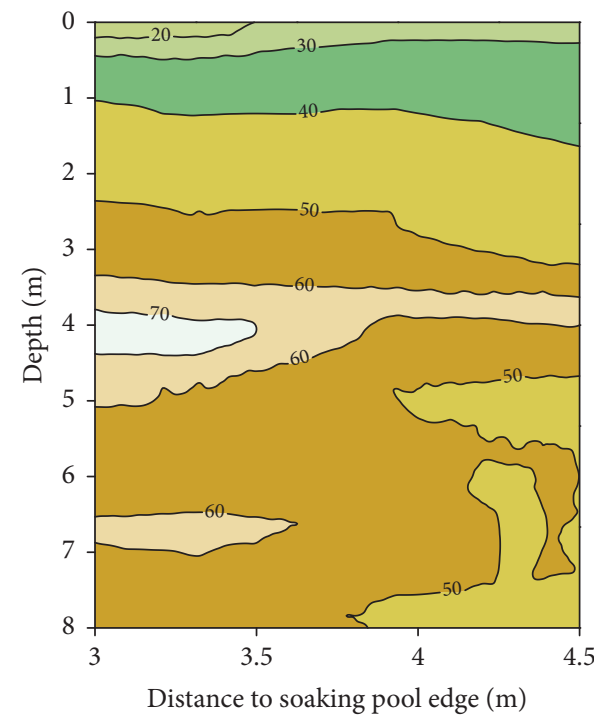

(f) $t=54 \mathrm{~d}_{\text {on }} \mathrm{OA}^{\prime}$ profile

FIgURE 6: Continued. 


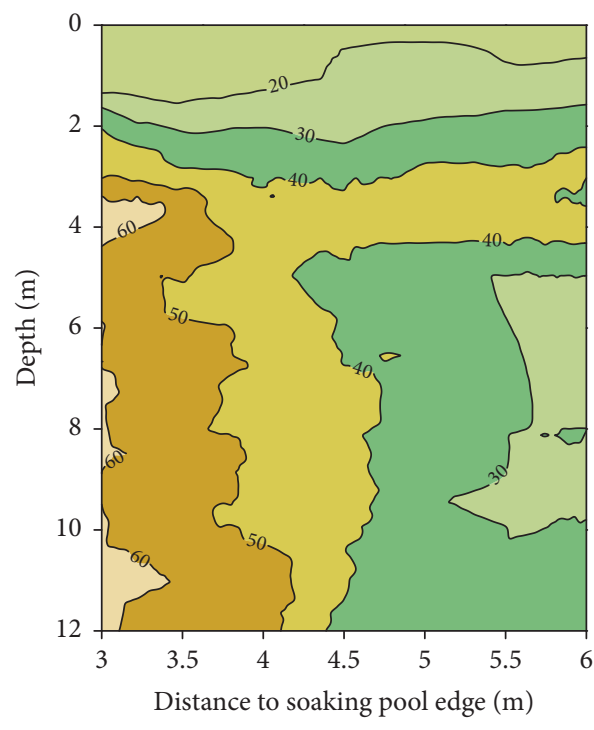

(g) $t=42 \mathrm{~d}$ on OB profile

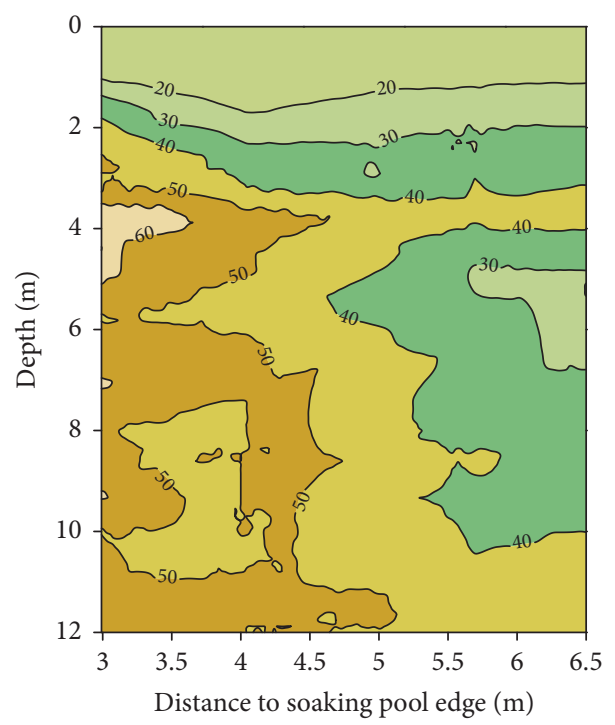

(i) $t=48 \mathrm{~d}$ on OC profile

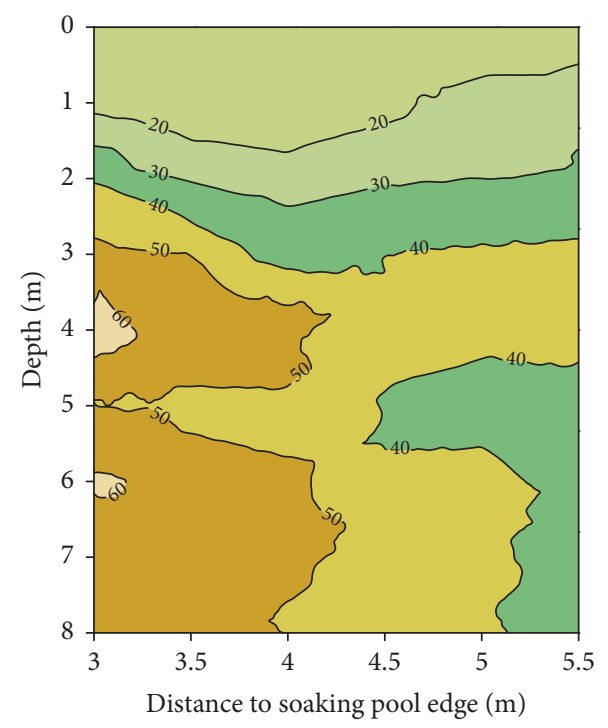

(h) $t=53 \mathrm{~d}_{\text {on }} \mathrm{OB}^{\prime}$ profile

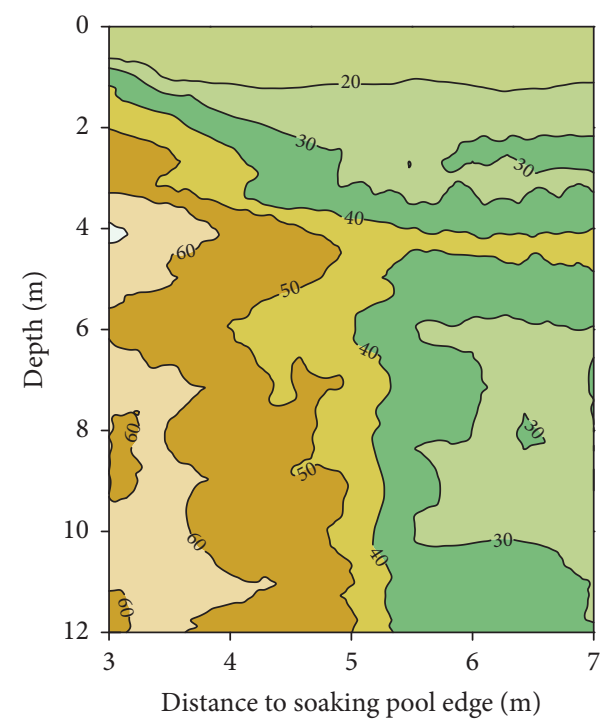

(j) $t=48 \mathrm{~d}$ on OE profile

Figure 6: Saturation isograms within the depth of 8 to $12 \mathrm{~m}$ at different time of soaking stages on typical profiles. (a-j) represent the profile of $\mathrm{OF}, \mathrm{OF}^{\prime}, \mathrm{OD}, \mathrm{OD}^{\prime}, \mathrm{OA}, \mathrm{OA}^{\prime}, \mathrm{OB}, \mathrm{OB}^{\prime}, \mathrm{OC}$, and $\mathrm{OE}$, respectively (see Figure 2(a)).

TABLE 4: Saturation permeability.

\begin{tabular}{lccc}
\hline Sample depth $(\mathrm{m})$ & $\begin{array}{c}\text { Average vertical hydraulic } \\
\text { conductivity } K_{v 10}(\mathrm{~cm} / \mathrm{s})\end{array}$ & $\begin{array}{c}\text { Average horizontal hydraulic } \\
\text { conductivity } K_{h 10}(\mathrm{~cm} / \mathrm{s})\end{array}$ & $K_{v 10} / K_{h 10}$ \\
\hline 2 & $6.3 \times 10^{-4}$ & $4.5 \times 10^{-4}$ & 1.40 \\
8 & $4.1 \times 10^{-5}$ & $3.8 \times 10^{-5}$ & 1.08 \\
\hline
\end{tabular}

of depth, which results in a loss of water potential energy, and (2) the occurrence and development of collapsibility cause a lot of soil compaction, which results in a decrease in void ratio.

On the other hand, the arrival time of water at various distances away from soaking pool was measured, as shown in Table 6. The horizontal infiltration characteristics showed that the horizontal wetting front was slower to make the move as the distance was farther away from the soaking pool, which is consistent with the results reported by the literature [34]. The reason is that matrix suction plays a limited role to drive the horizontal movement of wetting front. By comparing the infiltration rate of both directions, the vertical average value is $0.00697 \mathrm{~cm} / \mathrm{s}$, which is approximately 5.5 times the 


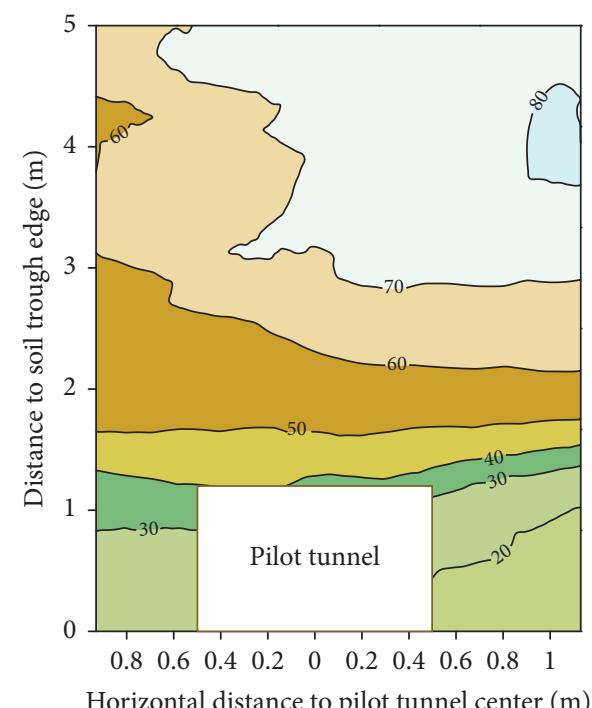

(a) $D=7.3 \mathrm{~m} ; t=38 \mathrm{~d}$

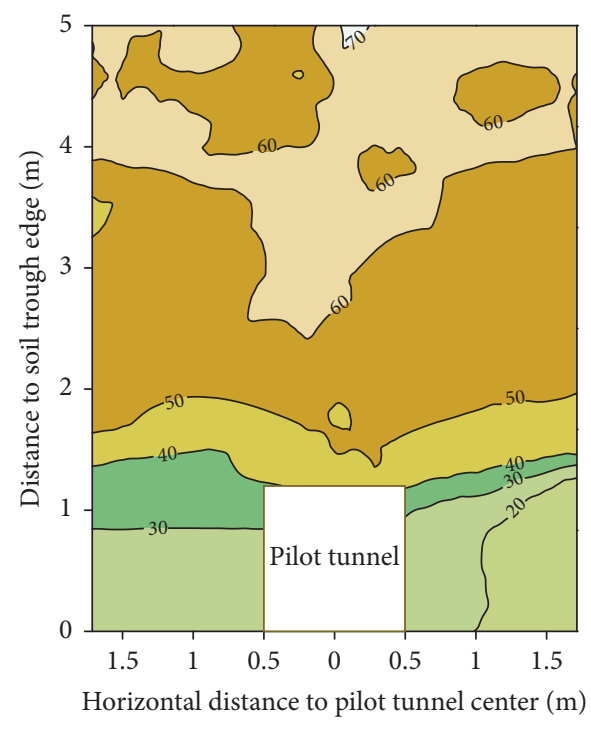

(b) $D=7 \mathrm{~m} ; t=41 \mathrm{~d}$

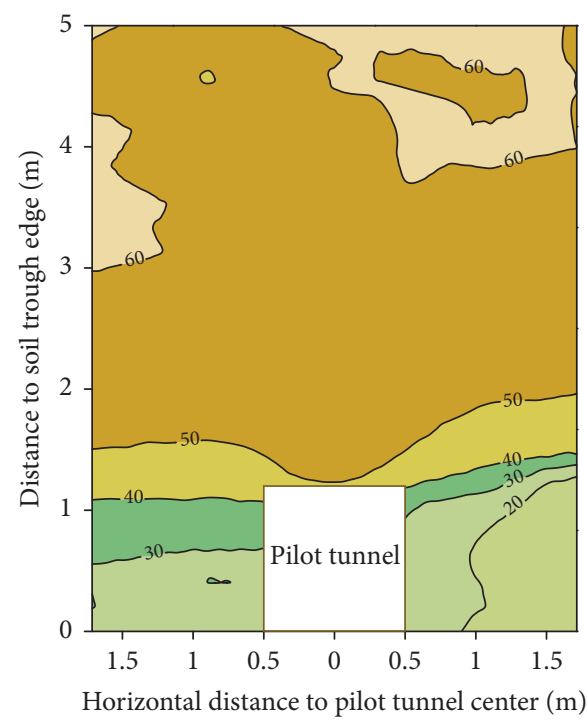

(c) $D=7.15 \mathrm{~m} ; t=43 \mathrm{~d}$

FIGURE 7: Saturation isograms after the excavation of pilot tunnel at different depth and soaking stages. (a-c) represent the depth of $D=7$ to $7.3 \mathrm{~m}$ and the soaking time of $t=38$ to $43 \mathrm{~d}$, respectively.

TABLE 5: Vertical infiltration rate (No. 4 probe).

\begin{tabular}{lcc}
\hline $\begin{array}{l}\text { Soil thickness } \\
(\mathrm{m})\end{array}$ & $\begin{array}{c}\text { Arrival time of water } \\
(\mathrm{h})\end{array}$ & $\begin{array}{c}\text { Infiltration rate } \\
(\mathrm{cm} / \mathrm{s})\end{array}$ \\
\hline 0.7 & 1 & 0.01944 \\
1.5 & 7 & 0.00595 \\
1.9 & 13 & 0.00406 \\
2.5 & 23 & 0.00302 \\
3.0 & 35 & 0.00238 \\
\hline
\end{tabular}

horizontal average value of $0.00126 \mathrm{~cm} / \mathrm{s}$. The inequivalence of horizontal and vertical infiltration rates reflects the special
TABLE 6: Horizontal infiltration rate (Depth of $2 \mathrm{~m}$ ).

\begin{tabular}{lcc}
\hline $\begin{array}{l}\text { Distance to soaking pool } \\
\text { edge }(\mathrm{m})\end{array}$ & $\begin{array}{c}\text { Arrival time of water } \\
(\mathrm{h})\end{array}$ & $\begin{array}{c}\text { Infiltration rate } \\
(\mathrm{cm} / \mathrm{s})\end{array}$ \\
\hline 0.3 & 12 & 0.00069 \\
3.0 & 30 & 0.00278 \\
4.0 & 360 & 0.00031 \\
\hline
\end{tabular}

structure of loess with root-like channels. Also, the movement of wetting front is due mainly to gravity and secondarily to matrix suction. 


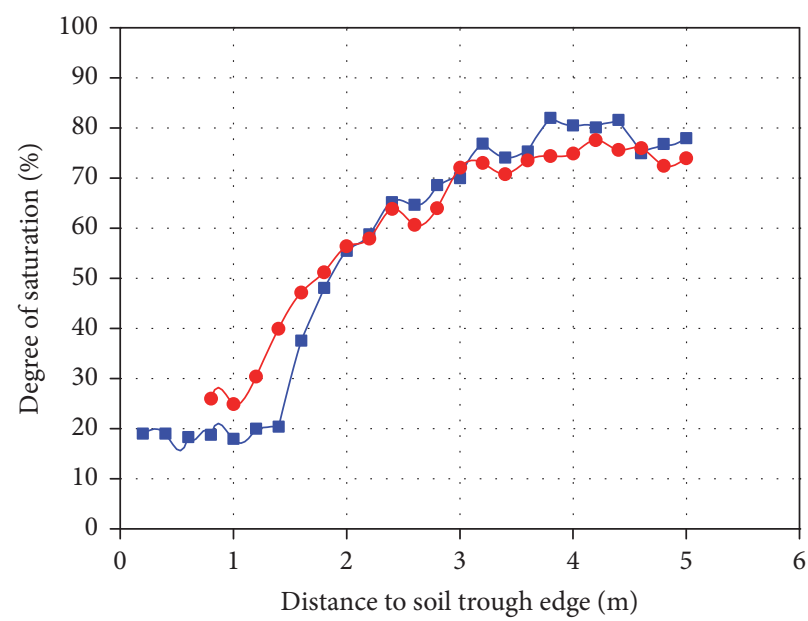

$\rightarrow$ Number 58 TRIME-TDR probe inside pilot tunnel - Number 59 TRIME-TDR probe outside pilot tunnel

(a) $L=0.8 \mathrm{~m} ; t=1 \mathrm{~d}$

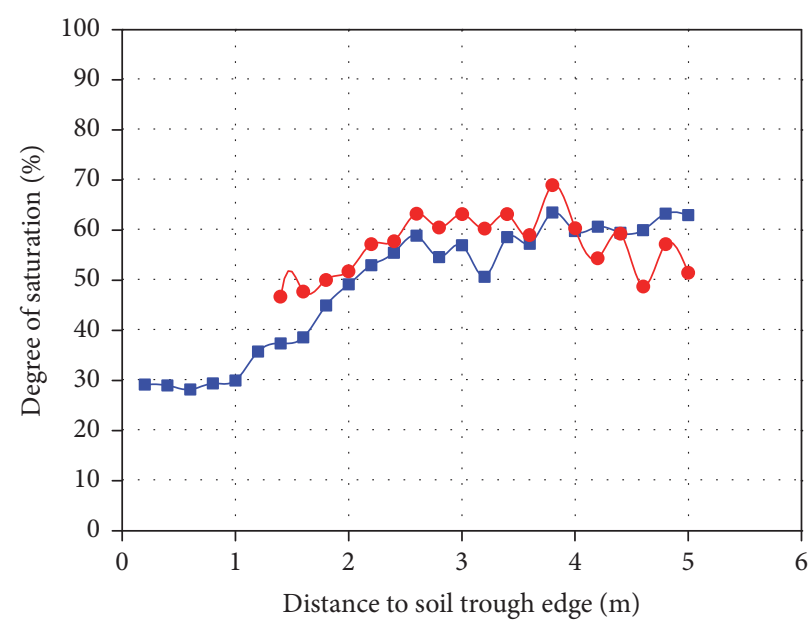

$\rightarrow$ Number 65 TRIME-TDR probe inside pilot tunnel

$\rightarrow$ Number 66 TRIME-TDR probe outside pilot tunnel

(b) $L=1.4 \mathrm{~m} ; t=3 \mathrm{~d}$

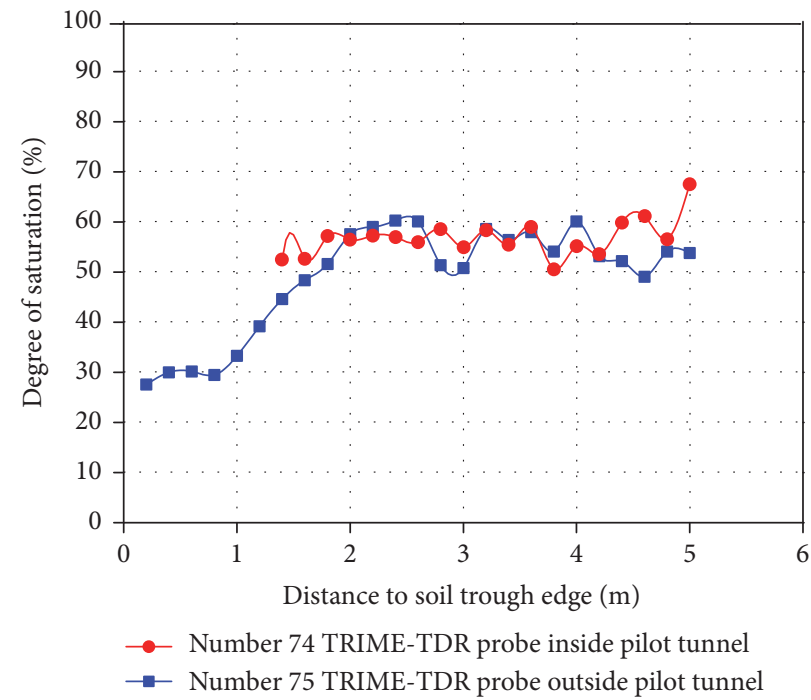

(c) $L=1.4 \mathrm{~m} ; t=5 \mathrm{~d}$

FIGURE 8: Saturation variation curves at different excavation stages during the soaking period. (a-c) represent the excavation length of $L=0.8$ to $1.4 \mathrm{~m}$ and the time of $t=1$ to $5 \mathrm{~d}$ after excavation, respectively.

\section{Conclusions}

In this paper, a large-scale field soaking experiment was conducted on collapsible loess in Lanzhou, China. TDR system and excavation sampling method were adopted for measuring the water content on typical profiles. The spatiotemporal evolution of infiltration behaviors was described by saturation isograms. The infiltration characteristics of collapsible loess were obtained as follows:

(1) In soaking experiment, unsaturated loess undergoes five stages at different depth: natural unsaturated status before soaking, unsaturated seepage status when wetting front passes, saturated seepage status after wetting front passes, unsaturated seepage status after water cutoff, and natural unsaturated status after a period of water cutoff.

(2) The downward movement of wetting front slowed down with an increase of depth. After cutting off the water supply, the shallower the depth was, the faster degree of saturation decreased.

(3) The movement of wetting front is due mainly to gravity and secondarily to matrix suction. Matrix suction contributes to a broader range of the movement of unsaturated wetting front and the movement of saturated wetting front is mainly driven by gravity.

(4) In unsaturated zone, the horizontal movement of wetting front was very slow-growing, while the vertical 

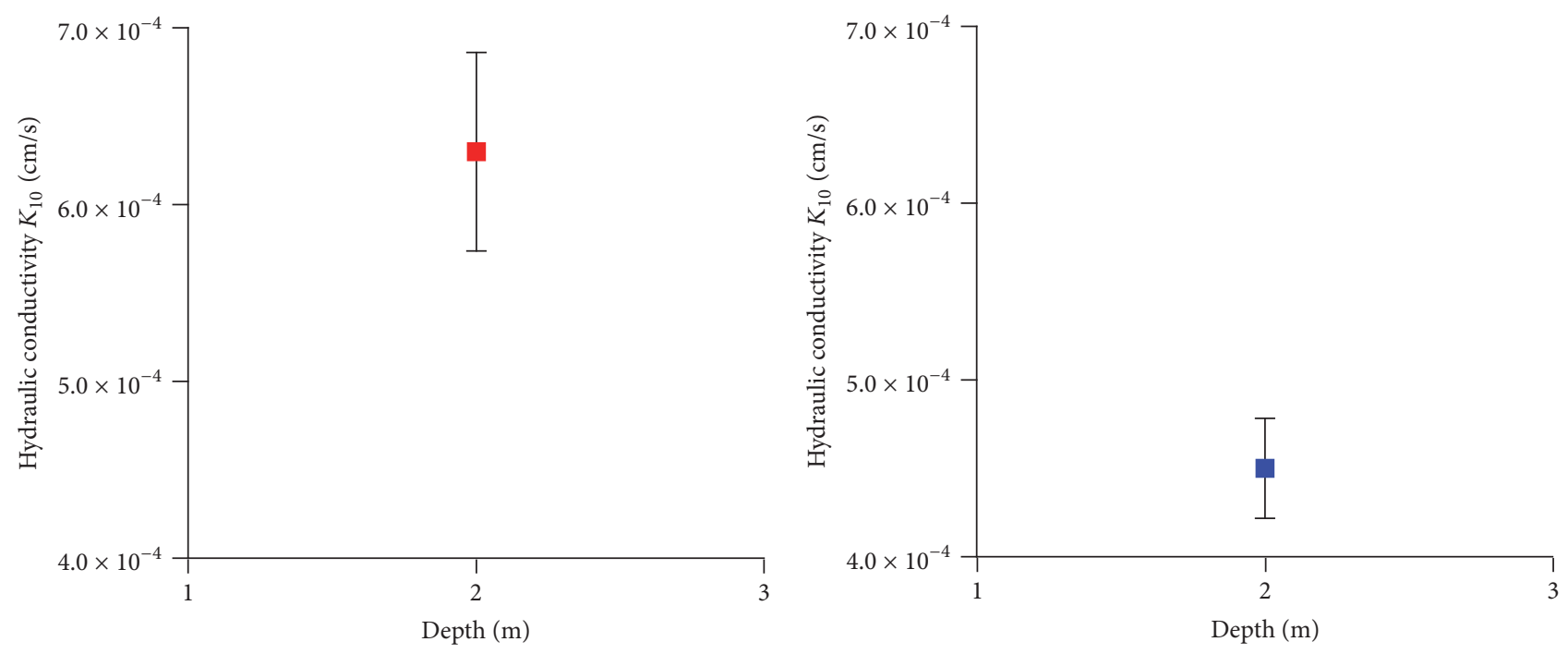

Vertical soil sample

Horizontal soil sample

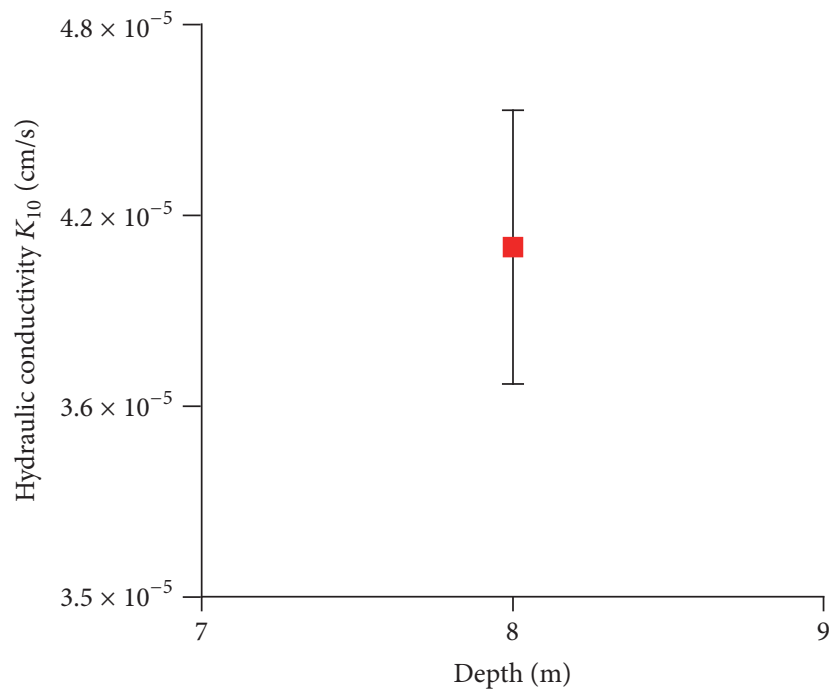

Vertical soil sample

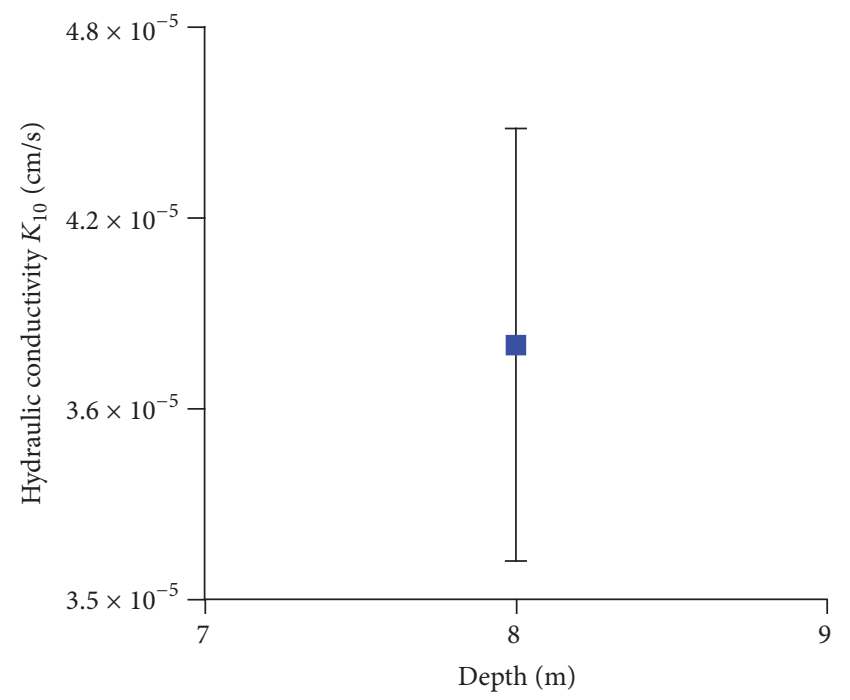

Horizontal soil sample

FIGURE 9: Average saturation permeability in vertical and horizontal directions.

movement of wetting front developed rapidly. The inequivalence of horizontal and vertical infiltration rates shows that the infiltration characteristic has typical anisotropism in both directions.

(5) Free face accelerated the horizontal movement of wetting front in unsaturated zone, particularly when the distance to soaking pool edge was less than $1.5 \mathrm{~m}$ and the degree of saturation was less than $50 \%$.

\section{Conflicts of Interest}

The authors declare that there are no conflicts of interest regarding the publication of this article.

\section{Acknowledgments}

This work is supported by the Special Fund for Basic Scientific Research of Central Colleges of Changan University (no. 310821172004, no. 310821153312, and no. 310821165011) and the Brainstorm Project on Social Development of Shaanxi Provincial Science and Technology Department (no. 2016SF412).

\section{References}

[1] I. Smalley, “"In-situ” theories of loess formation and the significance of the calcium-carbonate content of loess," Earth-Science Reviews, vol. 7, no. 2, pp. 67-85, 1971. 
[2] E. Derbyshire, T. A. Dijkstra, I. J. Smalley, and Y. Li, "Failure mechanisms in loess and the effects of moisture content changes on remoulded strength," Quaternary International, vol. 24, no. C, pp. 5-15, 1994.

[3] C. D. F. Rogers, T. A. Dijkstra, and I. J. Smalley, "Hydroconsolidation and subsidence of loess: Studies from China, Russia, North America and Europe. In memory of Jan Sajgalik," Engineering Geology, vol. 37, no. 2, pp. 83-113, 1994.

[4] R. S. Sharma and S. Singhal, "Preliminary observation on volumetric behavior of unsaturated collapsible loess," in Proceedings of the 4th International Conference on Unsaturated Soils, pp. 1017-1024, usa, April 2006.

[5] Y. M. Reznik, "Influence of physical properties on deformation characteristics of collapsible soils," Engineering Geology, vol. 92, no. 1-2, pp. 27-37, 2007.

[6] T. G. Ryashchenko, V. V. Akulova, and M. A. Erbaeva, "Loessial soils of Priangaria, Transbaikalia, Mongolia, and northwestern China," Quaternary International, vol. 179, no. 1, pp. 90-95, 2008.

[7] R. L. Parsons, R. M. Johnson, D. A. Brown, S. Dapp, and J. J. Brennan, "Characterization of Loess for Deep Foundations," DFI Journal - The Journal of the Deep Foundations Institute, vol. 3, no. 2, pp. 14-24, 2014.

[8] M. Jiang, H. Hu, and F. Liu, "Summary of collapsible behaviour of artificially structured loess in oedometer and triaxial wetting tests," Canadian Geotechnical Journal, vol. 49, no. 10, pp. 11471157, 2012.

[9] E. Derbyshire, "Geological hazards in loess terrain, with particular reference to the loess regions of China," Earth-Science Reviews, vol. 54, no. 1-3, pp. 231-260, 2001.

[10] Z. Liu, F. Liu, F. Ma et al., "Collapsibility, composition, and microstructure of loess in China," Canadian Geotechnical Journal, vol. 53, no. 4, pp. 673-686, 2016.

[11] P. Li, S. Vanapalli, and T. Li, "Review of collapse triggering mechanism of collapsible soils due to wetting," Journal of Rock Mechanics and Geotechnical Engineering, vol. 8, no. 2, pp. 256274, 2016.

[12] J. Lai, J. Qiu, H. Fan et al., "Fiber bragg grating sensors-based in situ monitoring and safety assessment of loess tunnel," Journal of Sensors, vol. 2016, Article ID 8658290, 10 pages, 2016.

[13] J. Lai, S. He, J. Qiu et al., "Characteristics of seismic disasters and aseismic measures of tunnels in Wenchuan earthquake," Environmental Earth Sciences, vol. 76, no. 2, article 94, 2017.

[14] J. Lai, H. Liu, J. Qiu et al., "Stress Analysis of CFG Pile Composite Foundation in Consolidating Saturated Mine Tailings Dam," Advances in Materials Science and Engineering, vol. 2016, Article ID 3948754, 2016.

[15] J. Lai, F. Niu, K. Wang et al., "Dynamic effect of metroinduced vibration on the rammed earth base of the Bell Tower," SpringerPlus, vol. 5, no. 1, article no. 935, 2016.

[16] D. Sun, D. Sheng, and S. W. Sloan, "Elastoplastic modelling of hydraulic and stress-strain behaviour of unsaturated soils," Mechanics of Materials, vol. 39, no. 3, pp. 212-221, 2007.

[17] D. Sheng, "Review of fundamental principles in modelling unsaturated soil behaviour," Computers and Geotechnics, vol. 38, no. 6, pp. 757-776, 2011.

[18] E. Rojas and O. Chávez, "Volumetric behavior of unsaturated soils," Canadian Geotechnical Journal, vol. 50, no. 2, pp. 209222, 2013.

[19] Q. Niu, D. Fratta, and Y.-H. Wang, "The use of electrical conductivity measurements in the prediction of hydraulic conductivity of unsaturated soils," Journal of Hydrology, vol. 522, pp. 475-487, 2015.

[20] Y. Gao, D. Sun, and A. Zhou, "Hydromechanical behaviour of unsaturated soil with different specimen preparations," Canadian Geotechnical Journal, vol. 53, no. 6, pp. 909-917, 2016.

[21] R. Tadepalli, H. Rahardjo, and D. G. Fredlund, "Measurements of matric suction and volume changes during inundation of collapsible soil," Geotechnical Testing Journal, vol. 15, no. 2, pp. 115-122, 1992.

[22] S. K. Vanapalli, D. G. Fredlund, D. E. Pufahl, and A. W. Clifton, "Model for the prediction of shear strength with respect to soil suction," Canadian Geotechnical Journal, vol. 33, no. 3, pp. 379392, 1996.

[23] P. Delage, M. D. Howat, and Y. J. Cui, "The relationship between suction and swelling properties in a heavily compacted unsaturated clay," Engineering Geology, vol. 50, no. 1-2, pp. 31-48, 1998.

[24] P. H. Simms and E. K. Yanful, "Measurement and estimation of pore shrinkage and pore distribution in a clayey till during soilwater characteristic curve tests," Canadian Geotechnical Journal, vol. 38, no. 4, pp. 741-754, 2001.

[25] A. M. Tang and Y. J. Cui, "Controlling suction by the vapour equilibrium technique at different temperatures and its application in determining the water retention properties of MX80 clay," Canadian Geotechnical Journal, vol. 42, no. 1, pp. 287-296, 2005.

[26] U. A. Aqtash and P. Bandini, "Prediction of unsaturated shear strength of an adobe soil from the soil-water characteristic curve," Construction and Building Materials, vol. 98, pp. 592599, 2015.

[27] R. Bashir, J. Sharma, and H. Stefaniak, "Effect of hysteresis of soil-water characteristic curves on infiltration under different climatic conditions," Canadian Geotechnical Journal, vol. 53, no. 2, pp. 273-284, 2015.

[28] K. Gavin and J. Xue, "A simple method to analyze infiltration into unsaturated soil slopes," Computers and Geotechnics, vol. 35, no. 2, pp. 223-230, 2008.

[29] J. A. Munoz-Castelblanco, J. M. Pereira, P. Delage, and Y. J. Cui, "The water retention properties of a natural unsaturated loess from northern France," Géotechnique, vol. 62, no. 2, pp. 95-106, 2012.

[30] S. M. Haeri, A. Khosravi, and S. Ghazizadeh, "The Measurement of Suction Stress Characteristic Curve for a Highly Collapsible Loessial Soil," in Proceedings of the IFCEE 2015, pp. 2482-2491, San Antonio, Texas.

[31] Y. Zhou, L. Tham, W. Yan, F. Dai, and L. Xu, "Laboratory study on soil behavior in loess slope subjected to infiltration," Engineering Geology, vol. 183, pp. 31-38, 2014.

[32] X. F. Huang and X. H. Yang, "A study progress on in-situ soaking test on collapsible loess," in Rock and Soil Mechanics. Volume 34, Issue S2, Pages 222-228. ( In Chinese, URL http, //dx.doi.org/10.16285/j.rsm.2013.s2.068, 2013, http://dx.doi.org/ 10.16285/j.rsm.2013.s2.068.

[33] X. Tu, A. Kwong, F. Dai, L. Tham, and H. Min, "Field monitoring of rainfall infiltration in a loess slope and analysis of failure mechanism of rainfall-induced landslides," Engineering Geology, vol. 105, no. 1-2, pp. 134-150, 2009.

[34] X. P. Wu, Study on the characteristics of collapse and permeability of large thickness loess ground based on water immersion test. PhD Thesis [Ph.D. thesis], In Chinese ), Lanzhou University, Lanzhou, Gansu, China, 2016. 
[35] Y. Kong, X. Huang, H. Ruan et al., "Study on vertical permeability regularity and collapsibility of a large thickness loess foundation by in-situ testing," E3S Web of Conferences, vol. 9, p. 05002, 2016.

[36] X. Wang, Y. Zhu, and X. Huang, "Field Tests on Deformation Property of Self-Weight Collapsible Loess with Large Thickness," International Journal of Geomechanics, vol. 14, no. 3, p. 04014001, 2014.

[37] J. X. Lai, H. B. Fan, J. X. Chen, J. L. Qiu, and K. Wang, "Blasting vibration monitoring of undercrossing railway tunnel using wireless sensor network," International Journal of Distributed Sensor Networks, vol. 2015, Article ID 703980, 7 pages, 2015.

[38] J. X. Lai, K. Y. Wang, and J. L. Qiu, "Vibration response characteristics of the cross tunnel structure," Shock and Vibration, vol. 2016, Article ID 9524206, 16 pages, 2016.

[39] J. X. Lai, S. Mao, J. L. Qiu et al., "Investigation progresses and applications of fractional derivative model in geotechnical engineering," Mathematical Problems in Engineering, vol. 2016, Article ID 9183296, 15 pages, 2016.

[40] J. X. Lai, J. L. Qiu, H. B. Fan, J. X. Chen, and Y. L. Xie, "Freezeproof method and test verification of a cold region tunnel employing electric heat tracing," Tunnelling and Underground Space Technology, vol. 60, pp. 56-65, 2016.

[41] J. Lai, Z. Feng, J. Qiu, J. Chen, and H. Fan, "In Situ Test of Grouting Reinforcement for Water-Enriched Sandy Gravel Ground in River Floodplain," Advances in Materials Science and Engineering, vol. 2016, Article ID 2129659, 2016.

[42] W. X. Wang, W. S. Zhao, L. X. Huang, V. Vimarlund, and Z. W. Wang, "Applications of terrestrial laser scanning for tunnels: a review," Journal of Traffic and Transportation Engineering (English Edition), vol. 1, no. 5, pp. 325-337, 2014.

[43] Y. B. Luo, J. X. Chen, W. Z. Xi et al., "Analysis of tunnel displacement accuracy with total station," Measurement, vol. 83, pp. 29-37, 2016.

[44] Y. Luo, J. Chen, P. Huang, M. Tang, X. Qiao, and Q. Liu, "Deformation and mechanical model of temporary support sidewall in tunnel cutting partial section," Tunnelling and Underground Space Technology, vol. 61, pp. 40-49, 2017.

[45] A. Thomsen, B. Hansen, and K. Schelde, "Application of TDR to water level measurement," Journal of Hydrology, vol. 236, no. 3-4, pp. 252-258, 2000.

[46] R. P. Chen, V. P. Drnevich, Y. Xiong, R. L. Nowack, and Y. M. Chen, "Time Domain Reflectometry Surface Reflections for Dielectric Constant," in in Highly Conductive Soils. of Geotechnical Geoenvironmental Engineering. Volume 133, Issue 12, Pages 1597-1608, ISSN 1090-0241, pp. 1090-0241, ASCE)10900241(2007)133, 12(1597, 2007, http://dx.doi.org/10.1061/.

[47] R. Černý, “Time-domain reflectometry method and its application for measuring moisture content in porous materials: A review," Measurement: Journal of the International Measurement Confederation, vol. 42, no. 3, pp. 329-336, 2009.

[48] K. Preko and H. Wilhelm, "Detection of water content inhomogeneities in a dike model using invasive GPR guided wave sounding and TRIME-TDR ${ }^{\circledR}$ technique," Journal of Geophysics and Engineering, vol. 9, no. 3, pp. 312-326, 2012.

[49] JTG, Test Methods of Soils for Highway Engineering, In Chinese), Professional Standards Compilation Group of Peoples Republic of China, Beijing, China, The, 2007.

[50] J. X. Lai, H. Q. Liu, J. L. Qiu, and J. Chen, "Settlement analysis of saturated tailings dam treated by CFG pile composite foundation," Advances in Materials Science and Engineering, vol. 2016, Article ID 7383762, 10 pages, 2016. 

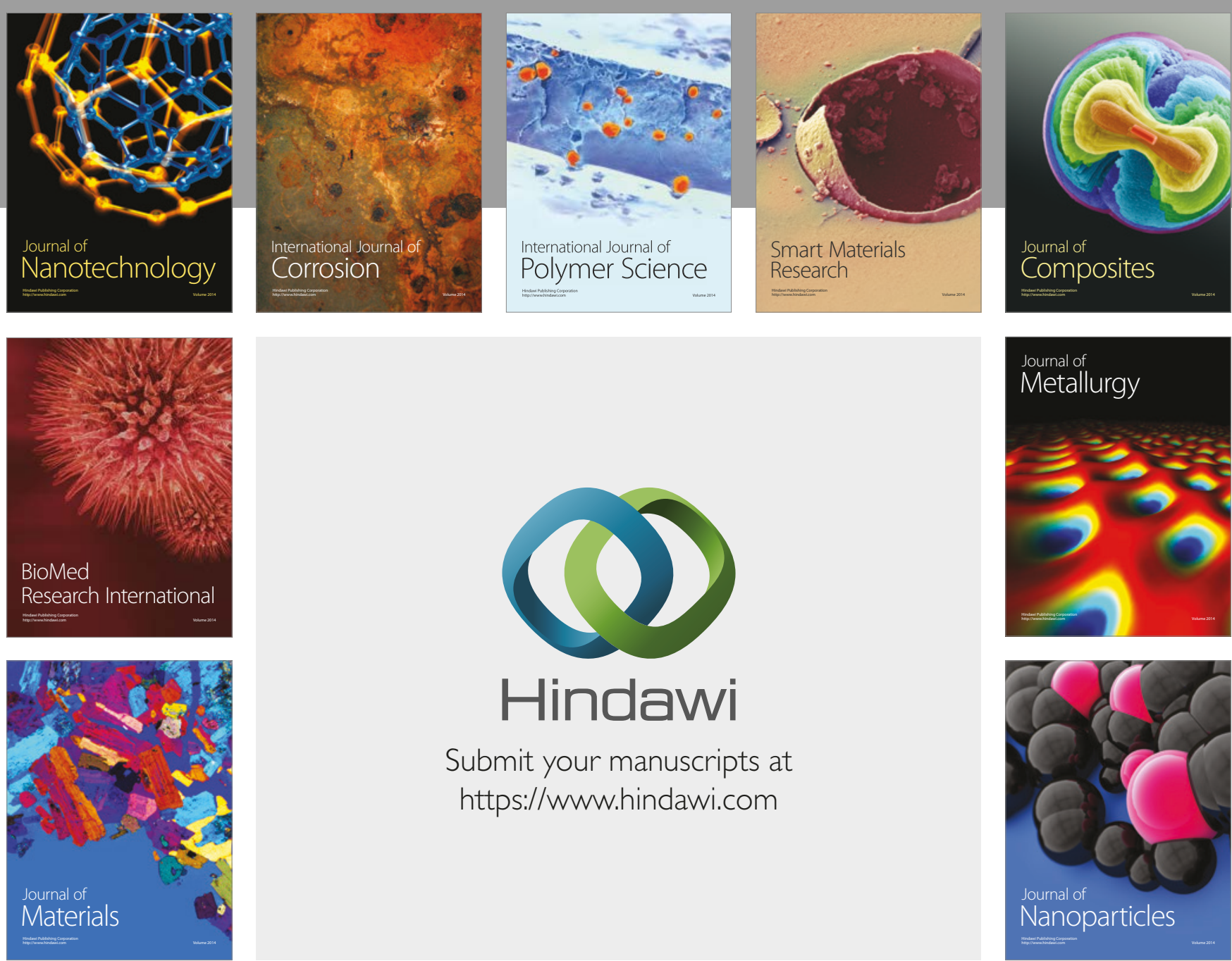

\section{Hindawi}

Submit your manuscripts at

https://www.hindawi.com
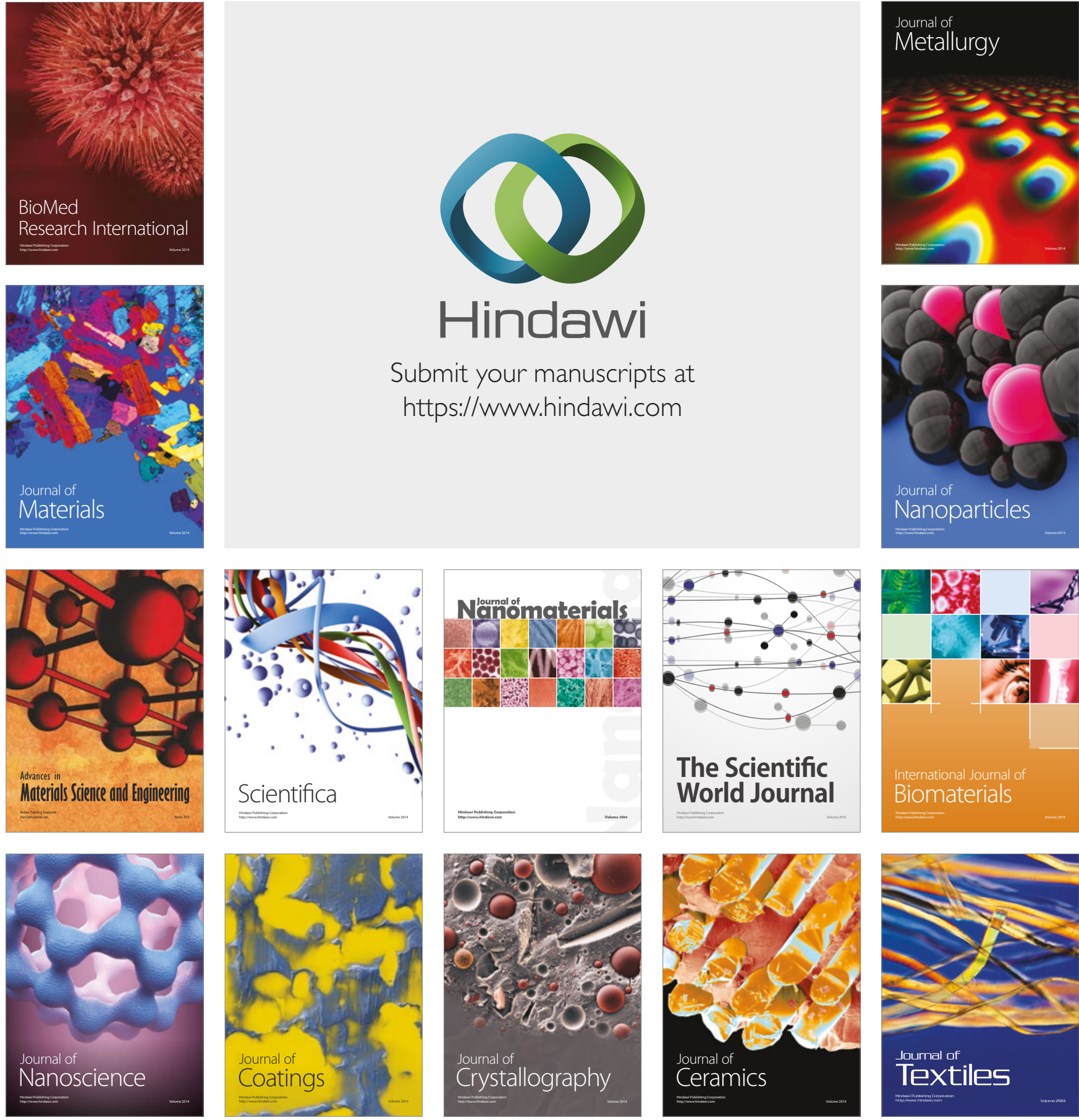

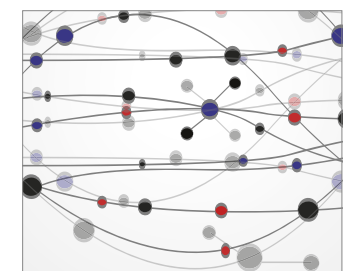

The Scientific World Journal
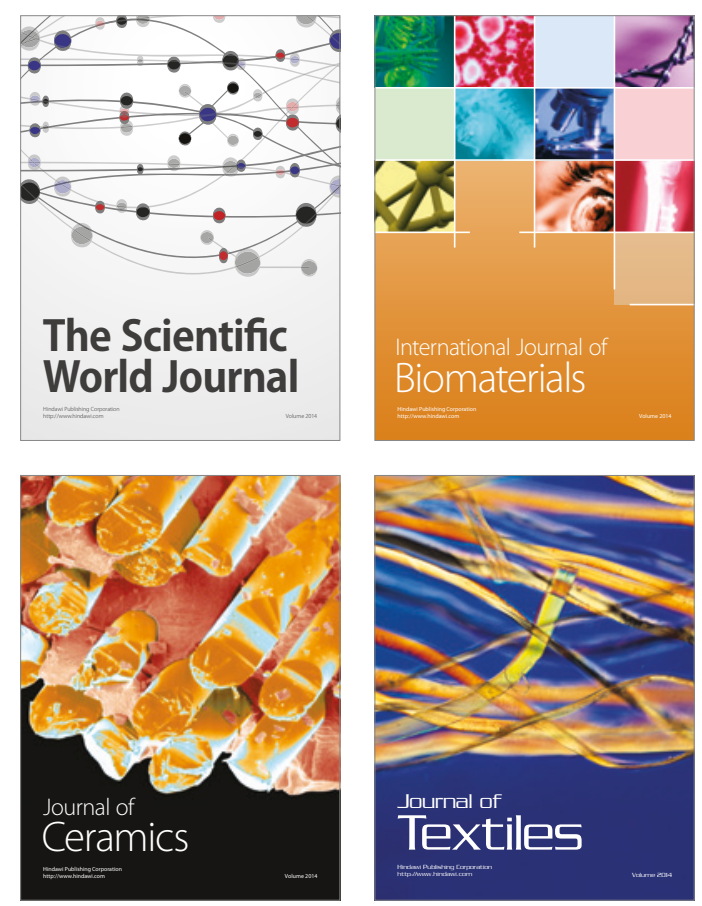